\title{
4
}

\section{Thought Bodies: Gender, Sex, Sexualities}

[B]odies are always 'thought bodies' or 'bodies-thought'-and perhaps one day we will look back on the 'sex-thought-body' that has so exercised our own century, our own repetitive and wearying anxiety about our sexual bodies, our commitments to the difference of gender that marks us so indelibly... with a certain wry amusement. (Rose, 1998, p. 183)

This chapter offers an exploration of the limits of binary thinking, and the multiple kinds of damage it causes. It offers three illustrations of complicitous situations that complicate a view of gender, sex and sexuality as understandable through binary thinking. Each illustration offered here has been rendered additionally difficult and painful by categorical thinking, the kind of thinking that the scientific method often depends upon and that the psy disciplines often perpetuate.

Thinking complicitously means getting outside of binary structures to conceptualize subjectivity as implicated in, not bounded from, otherness. It also means acknowledging we are implicated in the systems of power and meaning that make use of otherness. If race, as we have seen, is one constructed place where fixed identities emerge in response to histories of oppression authorized by binary thinking (which also means by ways of thinking that assert hierarchies of value for material profit), then gender is another. 
One of the urgent border wars being fought in the West at the moment is the struggle for transgender and nonbinary human being. As with the development and pathologization of racialized differences, psychology has had a central role to play in establishing meanings for and treatments of transgender and nonbinary people, as it has for sexual queers and for femininity and femaleness, all related (but not coterminous) histories of constructed meanings which gave rise to real, lived identities and material conditions of being. The first illustration provided here is an exploration of how transgender human being has been thought about in Western systems, including both the scientific and medical establishments, and feminist and queer theories.

I use the term "transgender" to refer to all people who occupy a gender identity different to the one assigned to them at birth, from within a binary system, on the basis of their perceived anatomy. Transgender people may or may not require hormonal or surgical gender affirmation. Some transgender people may occupy standard or standardized gender locations for "male" or "female." Some may identify as trans men or trans women, and some may identify as women or men who happen also have a transgender trajectory.

I use the term "non-binary" specifically to indicate those people whose gender identities cannot be accommodated within the gender binary. Sometimes nonbinary people need to enact a nonbinary embodiment with the help of medical interventions. Some nonbinary people will also be transgender. There are many other terms for noncisgender identities, and the list changes as the culture makes room and new iterations emerge. For the purposes of brevity, I include identities such as genderqueer or agender within the rubric of nonbinary. All of these markers are gender markers, and do not denote anything about sexuality or sexual orientation. Some transgender and/or nonbinary people will also be queer, which in this context means members of the LGBQ+ sexuality umbrella.

In the second illustration explored here, I move from gender to sexuality, and some of the structuring dynamics of normative heterosexuality. Another urgent conflict, sometimes conceptualized as equivalent to war (Faludi, 2006; Herman, 1997; Ward, 2020), is the struggle for sexual agency experienced by girls and women-in the terms of this discussion, this usually means those assigned female at birth (AFAB), although it can 
and should include those who are otherwise female or feminized-in this patriarchal culture.

Finally, I look at what emerges when genders and sexualities in another place have to make sense of themselves within neocolonial conditions. By examining the transnational complexities of Western LGBTQ ideas and identities in South Africa, I offer a third illustration of complicitous thinking about both gender and sexuality, as they can be taken together.

The topics of gender and sexuality offer a crucial opportunity for practitioners of the psy disciplines to see what theories developed in the humanities can offer us. Psychology has been implicated in the assertion of binary thinking, in the reinscription of science and biology as technologies for proving gender in always already gendered cultures in the name of objective truth. It has helped develop and perpetuate notions of sexual normativity (Drescher, 2015a) that are also, inevitably, deeply raced and classed (Carter, 2007). It is high time for the psy disciplines to think differently about gender, sex and sexuality, and to stop perpetuating norms as natural.

This chapter offers what I hope are useful, currently relevant insights into discussions that are at least as old as feminism itself, about the relationship between sex and gender, and about at least some aspects of normative (hetero)sexuality. In the evolving realms of transgender mental health, of sexuality studies and of decolonial imperatives within a transnational frame, these discussions are both urgent and in flux, the more we listen and learn.

All three of the examples presented here illustrate a problem with language. Each of the areas of human being explored in this chapter (transgender being; heteronormative female being; transnational queer being) demonstrates that language has shaping power, and that language gives or disables agency. If you do not have the words to describe an experience, it cannot be recognized by others, and it is much harder to make sense of it for yourself. If you do know your own meaning, but your words are dismissed or derided, your experience cannot be acknowledged or addressed. Each of the examples under discussion here tracks a struggle to find the words to articulate versions of human being that are othered within current systems of power. This is evidence of the importance of 
language as a human system, and of the symbolic as providing primary access to human subjectivity and processes of subjectification.

Starting with a brief overview of the evolution of gender within Western culture, this chapter offers comprehensive illustration of the constructed nature of apparently natural meanings, and how binary thinking shapes difference. In this way, it extends the arguments of the previous chapter, that apparently common sensical categories are historical formations, informed by the psy disciplines, among other disciplinary matrixes. We need to bring this thinking to our psychotherapeutic practice, in order to hold space in a way that can manage the complicities that are always at play within a client's sense of self, and between therapist and client. The question of practice is the main topic of the last chapter. Let us begin by reviewing what is perhaps the most powerful binary structure underlying Western culture.

\section{Binary Gender}

In practice, gender is complicated and personal, informed by each person's cultural and family dynamics as well as by their intimate experiences of themselves, both before and after language has had a go at shaping them. For example, Harris (2009) writes powerfully, from within a relational psychoanalytic frame, about gender's fundamental complexity, which is denied and reduced by a binary logic. She shows that gender is material, relational, actively assembled and contextual. It is made up of developmental events that may or may not directly relate to gender and/ or sexuality. It is both personal and collective; "It is as though gender were often the point of maximal psychic vulnerability, a flash point for the construction and maintenance of subjectivity" (Harris, 2009, p. 175). This is indeed a psychoanalytic understanding, which sees gender identity, achieved through sexuality, as instantiating the child's move into personhood via an encounter with the family, representing social rules, through the Oedipal process. Implicitly, therefore, gender is a key place where inherited social meanings enter subjectification.

Doan (2010) explores how, in addition to carrying interpersonal social meanings, gender is an interaction between a person and the kind of 
space that person moves through. Other people's presence in space helps bring different expectations and behaviors depending on the place that is shared. This is a visual, embodied geography of complicity to add to Harris's psychoanalytic one. If there is a place where the personal, the social, the historical, the embodied and the familial obviously combine to construct complicity - the place, the subject and their context cannot be delineated from each other-it is gender. This is so, even as gender often feels like the most personal of places, where we find our inner selves: complicity at work, making the subject.

As we will see, Western culture, assisted mightily by scientific thinking which wants categories, has a deep investment in denying the complicit content of gender. Patriarchy needs a gender binary. As discussed in Chap. 1, binary thinking enables a dynamics of psychic and material power.

Binary gender is also a Western attempt to make sense of sexual difference under patriarchy. This use of sexual difference has been theorized, by psychoanalytically informed thinkers, as productive of misogyny and sexism (Benjamin, 1988; De Lauretis, 1987; Dean \& Lane, 2001; Rose, 1986), as well as heteronormative heterosexuality (Butler, 1999). While this process has historical nuance (Perry, 2018), there is a larger theoretical point to be made here about some of the formative energies of the culture as a whole (see Gilmore, 2001).

Ward (2020) and Carter (2007) add the important point that the heteronormative gender binary, as it developed in America, is also raced. As I suggested in the previous chapter, this is inevitable, since gender and race co-constitute, as feminists of color have always said. Modern American heterosexuality was formed in and shaped by the early twentieth century (Katz, 2007). Eugenicist practices fundamentally informed the development of discourses of healthy heterosexuality, as circulated by the psy disciplines as well as medical and sexological interventions. Whiteness became the implicit human norm in part through these processes (Carter, 2007; Ward, 2020). Camminga (2019), too, shows connections between eugenics, sexology, racism and binary heteronormativity in early twentieth century South Africa, a site of interest to the eugenics movement in the North because of its highly racialized colonial dynamics.

There is a long genesis to binary gender logic in Western cultural and political systems, where people, in the first place white people, born with 
penises, have unmediated access to subjectivity, and everyone else has additional work to do. This assumption is Freud's starting point, as we saw in Chap. 2. Freud articulated overtly, in a discourse that became psychology, what up till then Western culture had taken for granted.

We can start tracking this with the first scientist of Western culture, Aristotle. Biologically, AFAB women cannot do what men do, produce semen, and this, for Aristotle_-and especially for the early modern era which "rediscovered" him-was evidence that they were incompletely human, "nothing else but an error or aberration of nature... yea the first monster in nature," as a 1615 summary of his position put it (Aughterson, 1998, p. 464; see Schiebinger, 1989). Nature therefore endorsed women's inferior social position in ancient Greek culture. Aristotle helped lay the groundwork for the idea that biology is destiny. Even apologists of Aristotle's views on women concede he takes for granted that men and women have different, complementary, biologically endorsed roles to play in society. Of course, this means women are not cut out for civic life, but are designed by nature to have, raise and stay with children as their raison d'etre (Dobbs, 1996). There are several familiar patriarchal assumptions at play here, which structure gender difference along the lines of different innate essences. These naturally give rise to different, complementary abilities: public and private capacities; intellect or mind versus body; or as Aristotle put it, form (the male) versus matter (the female).

These assumptions and structuring principles built on themselves (see Coole, 1988; Gilmore, 2001). The Greeks knew women were inferior to men, not able to think clearly or execute good judgment. In line with this, the sin of Eve came to contaminate women's meaning in medieval and early modern culture (see Distiller, 2008). The cultural story is that women cannot be trusted because they are penetratable (symbolically, by the snake's words, a sign of their constitutional and co-constituting physical, intellectual and moral weakness; women are, as the early modern period put it over and over, "leaky vessels"). Their bodies are the sign of their inferiority. Their bodies are also the source of their power over men. They can and, so goes the common cultural narrative, do use their bodies to tempt men, as Eve convinced Adam to fall. This suspicion of female sexuality remains powerfully present in the treatment rape survivors continue to receive today. Women are made responsible for eliciting men's 
desire, and ruthlessly punished for being desirable (see Gilmore, 2001; Ward, 2020). There is a logic of domination in this understanding of heteronormative desire (see Distiller, 2011). Binary thinking structures this dynamic, where the difference and otherness signified by the woman's body are simultaneously attractive, threatening and debased. This terrible, destructive difference must be controlled, or the gendered subjectivity which depends on keeping it out risks dissolution.

In the sixteenth and seventeenth centuries in Europe, there were vigorous debates over the nature of women, which tried to determine their proper social place (Beecher, 2005; Laqueur, 1992). Much of the debate concerned policing what they could wear, where they could occupy space and with whom. It was important to know what kept women's bodies in their proper place, since there was much cultural anxiety about loss of social distinction if women were allowed to dress like men, or vice versa (Levine, 1994; Orgel, 1996). There were, in fact, stories circulating at the time about women behaving inappropriately and thus turning into men (Laqueur, 1992). The control of women's bodies, then as now, was implicitly linked to the control of their public speech (Boose, 1991; Distiller, 2008; Jones, 1986; Vickers, 1981; Wall, 1993). It would make a fascinating project to compare the cultural texts that responded to Queen Elizabeth I, who, at the point of emergence of early modernity, brilliantly navigated the impossible contradiction of occupying a position of male authority with her female body, with the treatment of Hillary Clinton in the 2016 elections, as postmodernity seems poised to fracture under the representational pressures of social media (see Berry, 1989; Marotti, 1982; Solnit, 2018).

With the Enlightenment and the development of modern science, including psychology, came the cultural and economic idea of the individual as we now know him, as we have seen. In this time, drawing on colonial racism as well as centuries of sexism, Linnaeus developed his taxonomy of all things. He chose the term homo sapiens (meaning "man of wisdom") to emphasize the ways in which men are different to primates. He chose the term mammals, referring to the body part shared by only the females of all the species he was connecting, to denote what joined humans to animals (Schiebinger, 2004). The old binary meanings continued to influence new discourses, including Darwin's (see Saini, 
2017), where female bodies continued to be tied to lower, earthy, realms; to the apparent imperatives of (hetero)sexuality and their consequences (rape, pregnancy); to an emerging concept of "nature"; and to the reduced capacity for intellect and therefore personhood that started with the Ancient Greeks (see Schiebinger, 1989). French writer Gustave Le Bon, interested in both psychology and anthropology, opined in 1879:

[Women's] inferiority is so obvious that no one can contest it for a moment; only its degree is worth discussion. All psychologists who have studied the intelligence of women, as well as poets and novelists, recognize today that they represent the most inferior forms of human evolution and that they are closer to children and savages than to an adult, civilized man. They excel in fickleness, inconstancy, absence of thought and logic, and incapacity to reason. Without doubt there exist some very distinguished women, very superior to the average man, but they are as exceptional as the birth of any monstrosity as, for example, of a gorilla with two heads; consequently, we may neglect them entirely. (Qtd. Fisher 2011, p. 10)

Articulating for the first time the language of the unconscious of Western culture, Freud (1973) also said biology should be destiny, and since women self-evidently had nothing where the signifier of subjectivity should be, they needed to come to terms with their proper receptive place in the world, for the sake of the reproductive security of the race. Freud heteronormatively assumed that babies can only be made by heterosexuals in monogamous pairings (see Distiller, 2011), and require the unpaid labor of female bodies to survive, as a consequence of natural imperatives. Any other configuration, because to the Victorian mind unnatural, threatens proper human development, which finds its best expression in the creation of more monogamous heterosexual pairings. This assumption has structured the discipline of psychology and most of its offshoots until recently, and still exists as a powerful cultural norm. In this version of proper gender, linked to sex and sexuality, people assigned female at birth and who remain so are required to internalize and embody specific qualities and meanings. As always, race layers onto these pressures, adding meanings and rules (Cooper, 2018; Cruz, 2016; Perry, 2018; Ward, 2020), as does ablebodiedness (Drummond \& Brotman, 2014) and class (Yeskel, 2015). 
Binary gender is a core structural component of the self/other power dynamic that informs Western modernity and which enabled the colonial enterprises that gave us our twenty-first century global systems. It unconsciously drives much of what dominant institutions assume to be true about nature, about gender roles, about sexuality and about how they each inform the other.

\section{Transgender Complicities}

Despite the shaping assumptions of Western science, dominant culture and heteronormativity that gender is essentially binary in structure, gender is in fact made of a complicit structure. It is not, in lived reality, formed out of complementarity, where your gender is kept in place because it is not like the "other" gender. The very instability of this apparently natural and obvious relation gives it the lie; there are too many instances in history and in science of additional options for gender to be based in binary logic, or to be based on binary sex (Fausto-Sterling, 1993). Gender is complex, intertwined with heteronormative systems of oppression, as well as with histories of resistance and whatever personal assertions take shape in the contexts available to any given subject. There is not one original source of gender. Gender is put together by subjects of culture, language, history and family, and by the mediated sense we each make of biology, of how our bodies feel to us through the network of options made available to each of us by the worlds of possibilities and of limits we inherit.

Then there is the matter of how gender, after it is internally felt, is expressed, and what the relationship is between the two. Queer theory was partially built on the argument that the iterative social performance of gender helps to create the way it feels to be gendered (Butler, 1999). The implications are not only for the social meanings of gender or the subjective interpretations of gendered selfhood. Butler also famously asserted that gender is a performance which effects help to ensure that sex is always already gendered, and not the other way around (see also Butler, 1993); binary sex is not the bedrock of gender, but a consequence of it. The apparently unidirectional causal relationship between sex—genitals, 
hormones, chromosomes - and the social identities "male" and "female" is thereby broken. Gender and sex both exist through the doing of the socially sanctioned rules of gender which go on, as feminist historians of science and feminist scientists continue to show, to inform and shape our "scientific" understandings of sex and gender, and the biological meanings we make of sexual difference (e.g., Fausto-Sterling, 1992; FaustoSterling, 2000; Fine, 2014; Fisher, 2011; Haraway, 1989; Rippon, 2019; Saini, 2017; Schiebinger, 2004).

This gets complicated when we apply the queer and feminist thinking that opens up binary gender assumptions to the lives and self-narratives of some transgender people. As Prosser (1998, p. 43) puts it in his brilliant interrogation of the relationship between feminist and queer theories and transgender lives (he is writing in the period where transsexual and transgender were still sometimes being used interchangeably, and before nonbinary was a publicly recognized identity),

The transsexual doesn't necessarily look differently gendered but by definition feels differently gendered from her or his birth-assigned sex. In both its medical and its autobiographical versions, the transsexual narrative depends upon an initial crediting of this feeling as generative ground. It demands some recognition of the category of corporeal interiority (internal bodily sensations) and of its distinctiveness from that which can be seen (external surface): the difference between gender identity and sex that serves as the logic of transsexuality.

Many of us experience what it means to be a cisgender woman or man as natural, but queer theory teaches that that feeling is created through our participation in the repeated signals and signs that society provides us as the correct ways to be (also raced, classed, ablebodied or disabled) women or men. For many transgender people, and certainly for the medical and psychological discourses that authorize their being, the natural imperative comes directly from the body, and is at odds with the social rules being imposed on the body. As Prosser (1998, p. 67) shows, "transsexual autobiography challenge's theory's cynicism over identity's embodiment" (see also Califa, 1997; Serano, 2016). 
It is my assertion that the fact of transgender human being is perhaps the best case study we have so far in the complicit nature of gender. The embodiment of identity cannot be separated into constructed or performed gender, and sexed objective truth. The theoretical conundrum only arises if we remain committed to the binary formulation, where sex and gender are either/ors of each other, as has informed the debate about gender theory and transgender personhood. Each construct (sex, gender) draws on inherited systems of meaning and structures of expression to establish their intelligibility to themselves and each other. They inform each other. Each will have a personal meaning for each subject, whose pure epistemology we can never recover from the tangle of complicities that make us all. Thus trans does not need to remain in binary relation to cis. Following on from this, if we (the cisgender establishment) can accept trans personhood as within the realm of the human, we do not need to account for it. We can accept it, and learn from it.

I say this without wanting to reproduce the objectifying and instrumentalizing of trans personhood that has been committed by queer theory (see Prosser, 1998; Pyne, 2016). Transgender people are not theories or ideas, and their lives are often made much more difficult by the positions of otherness they are often forced to occupy (Grant et al., 2011). Transgender people are also not a coherent or homogenous group. There are as many different possibilities for transgender personhood as there are transgender people, even before intersectionality is added to the account. In theory, this is true for cisgender people too, if we can get beyond the strictures of the binary that wants to structure both our gender identities and our sexualities (Butler, 1999; Garber, 2005).

The theoretical conundrum that transgender personhood apparently presents to the queer and feminist theories that both enabled and used versions of transgender emergence is one example of complicity at work: sex versus gender is a binary construct, even as the psychic investments in asserting the truth of sex over gender were crucial for the emergence of transgender human being.

The structuring principle available for transgender emergence, which sets the terms for transgender human being to become intelligible, is another example of complicity. This latter set of terms, and the options they enabled for speaking transgender human being, is implicated in the 
psy technologies, as well as in sexology, endocrinology and surgery. Below, I will address these complicities in more detail.

First, there is a political point to be made. Sadly, the invocation of feminism in the context of a discussion about transgender personhood requires contextualization, given the deployment of putatively feminist arguments that are transphobic (starting, perhaps, with Raymond, 1979). Some people who call themselves feminist, relying on essentialized definitions of femaleness, would deny transgender people, especially trans women, the right to assume their correct gender. Building on a second wave logic which looked to reclaim the debased meaning of femaleness that was a result of the marriage of biology and gendered destiny, for these thinkers, being born and raised in a body with a vagina is the bottom line - and only legitimate-experience of femaleness. This reductive approach to the complex relations between the social rules for gender, embodiment, and victimhood or suffering overlooks the true gift of feminism: that none of us need be bound by a constructed relationship between gender and sex which strives to limit who we can be or how we can feel about our bodies.

Perry (2018) argues that the limitations of modern feminism are a result of the political processes of the twentieth century. These processes brought feminism into the mainstream, and thereby also into liberalism, whose politics of representation limited what was possible. Neoliberalism's fracturing of the social contract worked together with liberal commitments to affirmative action, so that as the twentieth century proceeded, "Rather than sharing prosperity, prosperity was made more competitive, exclusive, and slightly more diverse" (Perry, 2018, p. 91). The result, she says, is that in asking for a seat at the table, feminism had to align with the definitions of personhood that were available. The underlying necessary existence of the nonperson, discussed in the previous chapter, what Perry (2018, p. 93) calls the "monstrosity," was overlooked by these feminist strategies of inclusion. This was "a product of how we arrived at the institutional spaces where we have the conversation” (Perry, 2018, p. 93). In other words, participation requires complicity.

An investment in suffering - a way to find profit in one's sense of self - as the authorizing maneuver for access to both political and moral identity is one result of the neoliberal processes Perry (2018) tracks and 
discusses (see also brown 2020). This will be explored in more detail in the following two chapters, but it is worth noting here, as we explore why some people who know what gendered oppression is might seek to oppress other genders in turn.

Perry (2018) is theorizing how only certain categories of human being have been accommodated by mainstream feminism, that is, feminism that has achieved institutional recognition. Her larger project is to show how the legal category of human being in the West was historically constituted from practices which needed nonpersons as the constitutive other. To expand the terms of Perry's (2018) theory, trans and nonbinary persons are the unacknowledged nonpeople underpinning binary gender's rules for human being. "To embrace the monstrosity is to wrestle with the world from the status of the outside" (Perry, 2018, p. 97), as feminists of color did by "centering the position of the woman who existed outside personhood and theorizing from there" (ibid., p. 91). If there is one lesson to be learned from this, surely it is that our feminist work begins and ends with all those placed outside of the world. Apartheid, as a specific instantiation of white supremacy, imposed a racial hierarchy on people of color as a way to divide and conquer. This encouraged collaboration with the system. People who call themselves feminists but refuse transgender people's human being seem to me to be collaborating with the patriarchy that oppresses them, when they want to construct a hierarchy of access based on arguments about who has the right kind of bodies to deserve activist attention. There is more than enough patriarchally induced suffering to go round. Transgender justice is not a threat to cis women. It is the path to our liberation.

And, as we have started to see, just like trans-excluding "feminists," transgender being has typically been expressed through language that ties gender to the body. There has historically been an institutional investment in essentializing transgender experiences, reinscribing a narrative of wrong-body-based subjectivity that renders the trans person in need of binary-based medical transition to correct the biological error.

The coercive practices of the medical and psy disciplines that have constructed transgender people so as to interact with them have been welldocumented. In the early days of transsexual emergence in the 1950s, heteronormative and binary gendered performances were mandatory for 
those transgender people who needed to seek access to transition-related interventions (Bettcher, 2014; Califa, 1997; Denny, 2004; Pyne, 2016; Stryker, 2008; Tosh, 2016). Namaste (2000) has detailed how this history skews access to any evidence-based theories of trans "authenticity": Studies that inform diagnostic categories and best practices have traditionally been formulated from work done in gender clinics where trans people have been coerced into performing heteronormative binary gender before being allowed access to treatment.

This situation helped to create a cisnormatively-mediated discourse through which transgender subjectivity continues to be viewed (O'Shea, 2020; Spade, 2003). Since the 1990s, the experiences, languages and subjectivities of transgender, nonbinary and other differently gendered people have vastly expanded (Valentine, 2007). But there largely remains a nonnegotiable focus on the body that is an important element of being transgender (Bettcher, 2014; Langer, 2019; 2013; Pyne, 2016; Saketopoulou, 2014; Serano, 2016). Trans people continue to have to assert their knowledge that they exist in their own bodies.

It would be arrogant and dismissive of much carefully argued and important work to suggest that such narratives, of being in the wrong body, or of transgender being emerging from uncontestable body-based feelings and knowledge, were merely manipulation, at best, or false consciousness, at worst. Many transgender writers invoke this discourse to authorize themselves. Autobiographical writing (see, e.g., Califa, 1997; Feinberg, 1993; Prosser, 1998; Serano, 2016) and qualitative studies of the last two decades (see Levitt \& Ippolito, 2014) comprehensively document experiences of initial estrangement from self because of a core, but initially unexpressable, sense of one's gender identity, which can be exacerbated by negative responses to one's gender presentation. Wilkinson (2015) describes a process where personal, body-based truth intersects with social expectation and public treatment to create a necessary gender transition process. Thinking complicitously allows us to believe transgender speakers: they may be using what tools are available to them, socially and intrapsychically. But since we all do this, as a function of being human, and since we no longer assume binary thinking is necessary, we require no evidence from transgender people regarding the legitimacy of their existence, either in theory or in biology. 
This helps resolve the tension between queer theory and autobiographical felt truth. Kaufmann (qtd. in Pyne, 2016, p. 55) recounts,

Jessie, a self-identified male-to-female transsexual, was dismayed after reading a completed study in which I examined the narrative construction of her gender. Wiping tears from her eyes, she said, "You have taken away the identity I have worked all my life to build"... [M]y desire was to deconstruct gender, not erase her identity... How did I make such a mess?

Or, as Buckner (2016, p.76) shows, "While a social constructionist framework is empowering, it can also foster contempt, resentment, and critique of transgender embodiments that rely on essentialist, binary models of gender expression." One of Buckner's therapist respondents said,

Sometimes I get a little judgy when I hear people just, trans people, just stuck in that binary, you know? "I have to be a woman", you know? "I was born a man but I've always felt like a woman and I've got to be a woman and I'm going to be a woman"... and sometimes I get judgy and I think, why can't you just be you? ... Like why couldn't this person just be genderqueer? Or genderfluid? Or gender-something? Why did they have to be a woman?" (Buckner, 2016, p. 76)

This clearly denies the transgender client's experience of herself, and refuses her right and ability to articulate her gender and her body's relationship to it. And at the same time, there is a problematic history to the use of biology in the psychological understanding and treatment of trans people, where transgender identity has to come from a biological source.

Seeking to understand the etiology of transgender identity, in order to account for it, in a move which assumes it needs to be accounted for (to be legitimized? To be normalized? To be prevented?), there has been work on in-utero hormone exposure or prenatal gender developmental pathways which might have caused a transgender identity (e.g., the plenary lecture given at the WPATH conference by Dr. Karissa Sanbonmatsu, on November 7, 2020, titled, "Understanding gender identity: From DNA to the brain"; Zhou et al., 2007; Erickson-Schroth, 2013). Here, we once 
more see science believing it has answers to questions that are more correctly, more complexly, more complicitously, cultural-which is to say, both and always already constructed and biological, since our human experience of the biological must always be mediated, especially in a realm as fundamentally made of human being as gender. Thinking complicitously allows it all to be true: that many transgender people have a body-based truth which no-one, especially not an institutional gatekeeper, has the right to contest; and that transgender people, like all other people, can only put narrative constructions together from the symbolic histories available even as many of them also alter the available symbolic language as they use it, creating something new that is also real and legitimate (in a process akin to postcolonial processes of hybridity, and maybe even mimicry, theorized by Bhabha, 1994; see Distiller, 2012 for a cultural example of these ideas in practice).

And it is clear that transgender and nonbinary people have had to fight for symbolic space within the languages and the institutions that make us human. Writing about searching for space and speech as a differently gendered human within the confines of a scientifically-structured discipline (speech pathology), Azul (2018, p. 121) asks,

How to emerge from a condition of not-being-able-to-speak-and-notbeing-heard-with-what-one-has-to-say if the nature of one's voice-lessness cannot be explored with the methods of knowledge production in which one has been trained and if the promises of one's coming to voice cannot be accommodated within the constraints of the worldview according to which one has been raised?

Azul (2018, p. 122) critiques speech pathology definitions because they locate the problem in the speaker:

This is a form of voice-lessness... that does not appear in speech-language pathology dictionaries and text-books because its cause cannot be attributed to a malfunction of the speaker's psyche or their vocal folds... In fact, it appears unrelated to the voice producer as they are commonly understood, namely, as an entity from which that which we call "voice" emerges. Rather, this condition of voice-lessness seems to be imposed by the phonees, 
those who/which are exposed to vocal productions that have originated from elsewhere. Such phonee-imposed voice-lessness is characterized by the phonees' inability or refusal to acknowledge the presence and relevance of an utterance, by the phonees' lack of capacity or willingness to make sense of vibrations that have reached their senses.

Azul's (2018) notion of vocal productions that have originated from elsewhere which partially constitute the experience of nonbinary personhood through their refusal to allow it, to hear it speak its truth, is a perfect example of the foldedness, the outside-insideness of the subject of complicity (see Chap. 1). It also speaks to systems of oppression which plague the subject seeking to make language for itself or to assert its existence. The binary structures at work here cannot accommodate a nonbinary human speaking. And yet that human exists, and is speaking.

Azul (2018, p. 122) concludes, "research approaches are needed that seek to attend to the complexities of the participants' sociocultural positionings and to their preferences regarding how they wish to be perceived and addressed by others in encounters." The assertion here, in keeping with respecting the individual truth of gender's relation to the body, is that the gender outlaw (Bornstein, 1995; McKenzie, 2010) be allowed to vocalize/authorize/author themself, using and in so doing altering the available discourse. Azul (2018) offers an account of their own journey. They recount the damaging long-term psychic consequences of working in a scientific field which operated by categorizing bodies and their voices according to binary gender norms as part of its recognition of healthy human being. One of their points is the limitations of binary thinking. Another is that scientific or standard academic language cannot adequately account for this experience, this kind of knowledge. The call for a new model is clear.

In a special issue of the Journal of Gay \& Lesbian Psychotherapy, Denny (2004) worried about some of the negative consequences of rejecting the binary gender model intrinsic to the old medical model of transsexuality. He wondered if protection against discrimination and hate crimes would be extended to a nonspecific, "ambiguous or alternating" group, and about additional possible legal losses that would follow from depathologizing transgender identity (Denny, 2004, p. 32). In our identity-focused, 
liberal rights-based system, you have to be part of a recognizable group in order to be entitled to protections. There is also the risk that medical treatment will not be authorized if someone is not conceptualized as sick (Ettner, 2007).

Indeed, " $[\mathrm{M}]$ ost of the successful legal claims for trans equality have come through strategic use of the medical model of transsexuality" (Spade, 2003, p. 30; Spade demonstrates the disciplinary and formative relationship between medical systems, the law and gender intelligibility). Legal protections require not only assertions of group identity, but an alliance with the psy and medical disciplines that render transgender being intelligible and acceptable within the terms of a cisnormative symbolic.

In the psy disciplines, transgender personhood is indicated currently by the diagnosis of gender dysphoria. This controversial diagnosis has a telling history. It emerged from the perversions, later paraphilias and the struggle to remove homosexuality from the DSM (Bryant, 2006; Butler, 2004; De Bloch \& Adriaens, 2013; Drescher, 2015a; Drescher, 2015b; Lev, 2006; Wiggins, 2020). In other words, gender dysphoria has evolved through the long, convoluted history of the medical and psychological establishments' attempts to classify and pathologize gender and sexual deviations from the binary hetero norm. In the past few decades, activism from transgender and nonbinary people, clinicians and clients (Markman, 2011; Spade, 2003), has resulted in some changes for the better. In 2022, the World Health Organization's manual, the International Classification of Diseases (ICD) 11, will do away with its previous diagnosis of "transsexualism" and instead have "gender incongruence," which is a sexual health and not a mental health diagnosis (Atienza-Macías, 2020). This is progress. However, the requirement for transgender and other gender diverse people to have a diagnosis before being legible to the system and able to access interventions if they are needed remains problematic.

In line with an increasing call to have cisgender people step away from the policing of trans lives, Wiggins (2020) suggests that the medicalization of transgender distress be turned on the largely, and historically, cisgender clinicians who wield it. The investment in categorizing trans suffering (as gender dysphoria) as the new diagnostic replacement for the older frame of perversion is itself a perversion: a sign of cis disavowal of 
the anxiety caused by an encounter with gender difference. Because "the more a gender is assumed to be static, ciscentric, and knowable, as is encouraged in most Western medical, colonial contexts, the more foreboding would be a confrontation with its variance" (Wiggins, 2020, p. 66). In truth, the "traumatizing reality" is that "gender is uncertain, its affects and genealogies are unclear" (ibid, p. 69). This is a beautiful extension of the old feminist investigations into sexual difference as a constituting problem for patriarchy's symbolic work. It is also a logical extension of the queer deconstruction of the body as the underlying source of gender, where gender becomes sex. Gender difference, instead of sexual difference, becomes the destabilizing force that binary thinking needs to control. If we allow transgender experience into the realm of the human, the body is always real, even as it is also malleable and constructed. Sex is available to be a felt truth and a construct reliant on gender at the same time, because this is what human being is. This is complicity in action. Or, as Buckner (2016, p.53) puts it, the "stark divide" between transgender narratives of essential biological truth and queer theories of gender as socially constructed and reified through doing, "implodes in practical application."

Wiggins (2020, p. 69) suggests that the psy disciplines' manifestation of perversion is the fetished object of the DSM, the diagnostic manual whose evolution of definition for transgender being controls access to medical interventions and also grants cultural meaning to transgender being. Pace Freud, Wiggins argues,

A perverse defense uses the fetish object to purchase certainty and control in the face of variability and lack. And although this object may allow for the fantasy of knowing, it does so at the expense of possibility and of a receptiveness to difference.

This is a turning back on the psychological establishment of the frame used to understand, assess and approach transgender people. Wiggins (2020) suggests that perversion can be used as a structure of thought, freed from Freud's Oedipal, biology-based and culturally specific meanings. By this argument, the clinical requirement of transgender distress is the perverse fetish at the heart of Western and psychological culture. 
This is not to deny the burden borne by transgender communities, and especially by poor trans women of color: "That we live and die unliveable lives is not an academic abstraction but the brute reality of an often transphobic contemporary society" (O'Shea, 2020, p. 2). But it is to challenge the fact of transgender life as the source of the suffering, and to place it instead on transphobia. Such a move, taken to its full potential, would obviate the need for a diagnosis for transgender experience. If transgender humanity were accepted as such, without othering from a cisgender norm, the rigidity of binary gender and the connections to sex underneath, it would be broken once and for all. Sex could be gender without bodies being rendered irrelevant. A new culture would be possible. This is not an attempt to symbolically use the fact of transgender personhood to argue for a queering of the gender binary. It is an attempt to take seriously the lived realities of transgender people, to accept that embodied subjectivity is a right belonging to all humans regardless of the source, since embodied subjectivity is the complicit heart of our complicit being (and the key to therapy, as explored in Chap. 6). It is to argue that trans exclusion from the realm of the healthily human is a result of binary gender rules.

So what should cisgender clinicians do? The gender affirmative model (Hidalgo et al., 2013; Keo-Meier \& Ehrensaft, 2018) has developed in response to the medicalization and pathologization of transgender people. It marked what Pyne (2014, p. 1) calls "a paradigm shift: from disorder to diversity, from treatment to affirmation, from pathology to pride, from cure to community." As Denny (2004, p. 34) says,

There is a world of difference when both the therapist and the patient believe the patient to be mentally ill and in crisis, and when both the therapist and the client believe the client to be healthy and self-actualized and contemplating a life-altering decision [such as transition].

In addition, the purpose of therapy is no longer assumed to be to consider transition, or only one form of transition. The gender affirmative approach normalizes gender fluidity as an aspect of human diversity, and places any pathology on the culture's response to the trans person. It defines gender as being the result of a complex interweaving between 
biology and socialization, and one that has a culturally specific component as well (Hidalgo et al., 2013).

As Lev (2004, p. 4) puts it, "clinicians need to ask what it means to be a healthy, functioning gender-variant person within an immutable, dualgendered world." It means, in part, owning the almost inevitable misattunement that will follow, as cisgender clinicians have to explore their own formation within symbolic systems that did not consider trans humanity as a norm, or at all. It means knowing that biology is not destiny and gender is culture, and that the person you are sitting with may have an embodied, unarguably physical experience, empirical and not discursive, which needs to be believed. We have to hold that gender is a construct, a highly invested, artificial projection onto, or use of, the difference that exists in kinds of bodies on the human spectrum. Certainly, the fiction that gender, and the sex on which it is supposedly based, can only be an either/or is not even scientifically true. And in the structures of the world, which enable human being, there are many transgender people who experience their gendered selves as unarguably embodied, sometimes "across" binary gender. It really does not matter why, unless we need to find reasons to underwrite transgender humanity instead of just accepting it.

A theory of complicity allows for all the both-ands at play here. Gender identity and gender experience are highly personal and also totally mediated, including through medical and psychological discourses that seek transgender causality in the body. Theories of core gender are located within scientific and clinical models that legitimate transgender personhood through biological arguments. Deconstructive theories want to free gender from biology, in the first place for the emancipation of people born with vaginas and usually also uteruses in a culture that has always wanted to control and delimit them accordingly.

\section{Heterosexual Consent}

The question of whether women can truly consent to sex with men within a patriarchal world order is not a new one in feminist theory (Brownmiller, 2007; MacKinnon, 1989; Rich, 1980). In this section, I want to revisit 
the question of how the binary positions made possible by heteronormative heterosexuality continue to structure subjectivities within, and shape the institution of, heterosexual intimacy. Thinking complicitously in this situation complicates binary notions of victimhood, while allowing us to continue to insist on structural oppression and the harm it causes.

Since we all breathe in the smog of socialization (Tatum, 1997), people gendered female are formed in specific ways, to greater or lesser degrees and by resistance as well as acceptance, by the rules connecting bodies, genders and sexualities. Active female desire, independent female agency and assertive female speech (Distiller, 2008; Distiller, 2011) remain problematic for this culture and not uncomplicated for feminized people to access (Faludi, 2006; Levy, 2006). This can be particularly acute in those moments where the rules of gender intersect with deeply individualized meanings and experiences in the realm of sexuality. If, as Mitchell (1982, p. 2) asserts in her introduction to Lacan's Feminine Sexuality, "a person is formed through their sexuality," then AFAB subjectivity cannot help but be fundamentally implicated in the misogyny of heteronormative heterosexuality.

We inhabit a rape culture (Brownmiller, 2007; Gavey, 2019; Gay, 2018; Gqola, 2015; Solnit, 2014), and all women and feminized people have to survive this. Rape culture says that girls and women exist in order to be heterosexual sexual objects, and that heterosexual men are entitled to act on their desire for these objects when and as they like. It is a norm of conduct (Young \& Hegarty, 2019). Some AFAB and other females learn ways to find some profit in it, to get by or make the best of it. Some inevitably collude (see Faludi, 2006; Levy, 2006).

In The tragedy of heterosexuality, Ward (2020, p. 151) explores the implications for heterosexuality of the research findings, some of which are discussed below, of the fact that,

$[\mathrm{U}]$ nwanted sex inside heterosexual relationships is so common and normalized that it is a core part of the scaffolding of rape culture; there's a thin line between unwanted sex (the kind that many women have with husbands and boyfriends all the time) and sexual assault.

Sexual violence has, as far as we know in this culture, always been a common experience of AFAB sexuality, and from there, all female sexuality. Ward (2020, p. 27) writes about what she calls the "misogyny paradox": 
that men's heterosexual desire for women, the apparent fact that boys and men must love, need and want women, takes shape in a straight culture that also encourages them to hate, demean, hurt and control women (see Gilmore, 2001).

Consent was in the news a lot when, in 2017, the MeToo movement achieved international prominence after having been in circulation since 2006 in the work of African American feminist Tarana Burke (see Mendes et al., 2018; Rodino-Colocino, 2018). The recent public discussions about sexual harassment in the workplace, and sexual assault more broadly, mark an important cultural moment-yes, it happens! It happens a lot! No, women don't like it! — even as the predictable backlash kicked in almost as soon as the conversation began-not all men! But some women abuse their sexual power! (see Peleg-Koriat \& KlarChalamish, 2020). The popular cultural conversation falters in its lack of focus on structural issues and its emphasis on individual intent. In a similar way to the good white/bad white binary that DiAngelo (2018) points out prevents any real discussion of the structural workings of white supremacy, the assumption is that only bad men commit only egregious acts of sexual harassment and violation. The focus is on individual intention rather than the culture that authorizes the treatment of females as objects for heteronormative male gratification. This greatly reduces the change that can come out of a mainstream conversation in American society about what it is like to navigate the public realm in a female or feminized body (see Rodino-Colocino, 2018). But the workings of rape culture do not stay only in the public realm, and its consequences are not only patently, violently egregious. In ways specific to their experiences and expectations of sexuality and sexual intimacy, heterosexual women often internalize the limiting of their agency that is part and parcel of their cultural objectification.

Ward's (2020) book dedication is, "For straight women. May you find a way to have your sexual needs met without suffering so much." She points out, by exploring straight culture, that the apparent benefits and promises of heterosexuality in a heteronormative world - that it is better to be straight, and it will make you happier than being a marginalized queer-is not at all true, especially once intersectionality is considered. "Perhaps most urgently," she (Ward, 2020, p. 3) writes, 
[A]n important indicator of the relatively negligible value of heterosexuality for many women is the fact that their sexual relationships with men have been maintained by force, both through cultural propaganda.... and more directly through sexual assault, incest, compulsory marriage, economic dependence, control of children, and domestic violence.

These forces are a direct result of the cultural objectification of women which relies on a model of gender as binary, complementary and hierarchical. This symbolic economy underlies systems, institutions and structures which oppress females and feminized people. Ward (2020) shows that in its current form, heterosexuality is misogynistic and coercive of straight women, that heterosexuality is, in fact, "a patriarchal institution" (Ward, 2020, p. 16; see Butler, 1999; Katz, 2007; Rich, 1980). Binary logic is how it works. Documenting in detail the ways that many straight men seem to disrespect and dislike women, and that many women settle for what straight men do, Ward (2020, p. 16) comments,

Often propelled by the essentialist and heteronormative logic that male and female "energies" are incomplete without each other or that "opposites attract"..., straight culture seems to rely on blind acceptance that women and men do not need to hold the other gender in high esteem as much as they need to need each other and learn how to compromise and suppress their disappointment in the service of this need.

The consequences are material (women still do much more unpaid domestic labor and childcare work as well as holding down paid jobs; women still get paid less than men for the same work in America, with black women and women of color faring worse than white women, Faludi, 2006; Lockman, 2019); emotional (the sadness, disappointment, exhaustion, frustration, hopelessness and, for men, anger, insecurity and violence that come from thwarted entitlement, Ward, 2020) and, of course, sexual.

Thomas et al. (2017) track how straight women negotiate interpersonally and psychologically the "unwanted sex" that is an ordinary part of their sexual relationships and experiences. Pretending to consent becomes one way to manage sexual encounters. As this suggests, in twenty-first 
century consent studies, a binary view of consent is problematized: wanting is not the same as consenting; someone can be ambivalent and social scripts can conflict with bodily desires (Peterson \& Muehlenhard, 2007). Straight women can and do consent without desire, disturbingly often (Thomas et al., 2017; Ward, 2020). "Unidimensional, dichotomous conceptualizations of wantedness" (Peterson \& Muehlenhard, 2007, p. 72) do not capture the complexities of intrapersonal and interpersonal heterosexual dynamics (for an example of the difference that class makes, see Bay-Chen \& Bruns, 2016).

This includes agreement about what constitutes sex and when sex is over, which is usually with male orgasm (see also Ward, 2020). Gattuso (2016) tells it like it is:

Alas, friend of mine, you have had an orgasm and are falling asleep. I have not had an orgasm and am not falling asleep, which means I am awake, which means I am now going to lecture you... Who are you?... You are anyman, everyman,... You're a decent guy... No, you're not a bad guy. The sex wasn't particularly bad, either... It was normal sex. Normal, boring, vaguely dehumanizing hetero sex.

Which is precisely the point: The normalcy...

Here, supposedly, is what you consider sex: We make out, you play with my boobs... Penis goes in vagina, penis moves in and out of vagina... penis ejaculates.

You roll off of me, get up, take the condom off/pee/do whatever it is people with penises do in the bathroom immediately after they've come (world's great, great mysteries), put your pants on, come back into bed, and fall asleep. Sex is now over. Sex is now over because you have decided it is over. You have decided sex is over because you are a man, and because this choreography that favors men with penises-man becomes erect, man penetrates woman, man ejaculates—is what we have been told sex is...

$[\mathrm{Y}]$ ou need to know-that the way you conceptualize pleasure and its choreography is not the way sex inevitably is.

The "implicit rules of heterosex" (Thomas et al., 2017, p. 283) also include that her orgasm is a sign of his prowess, and must be clearly indicated via specific behaviors. This, suggest the authors, continues to encourage women to fake orgasm, despite "postfeminist" notions of 
"freedom and choice" which position women's sexual agency as equal to men's, as apolitical and as entirely personal (this is consistently understood to be a consequence of neoliberal formations, as will be seen in the next chapter; see Chowdhury \& Gibson, 2019; Gill \& Orgad, 2018; see also McClelland, 2010). However, "power imbalances are concealed in this repackaged construction," not least because, "female sexuality continues to be understood predominantly in relation to male sexuality and ultimately to heterosexual intercourse" (Thomas et al., 2017, p. 282).

Heterosexual women engage in a specific kind of sex work in the name of love; "In the context of gendered discourses of sexual performance that privilege male pleasure, faking orgasm can be seen as emotional labour" (Thomas et al., 2017, p. 283). At the same time, faking orgasm can also be read as a political act, to enable sex to end. Thus, "The simultaneous positioning of (fake) orgasms as emotional labour and as an agentic practice trouble the taken-for-granted understandings of female sexual desire, pleasure, and consent in heterosex" (Thomas et al., 2017, p. 283).

Consent as a construct has not been comprehensively or consistently defined (Peterson \& Muehlenhard, 2007). And after conducting a literature review on the topic, Beres (2007, p. 94) comments, "Even within the literature on sexual consent there is no consensus on what it is, how it should be defined or how it is communicated." She asks how we know if sexual violence has occurred if there is no clear definition of consent. "I know it when I see it" (Beres, 2007, p. 94) does not prove to be a reliable metric, she says, and argues that the meaning of consent is produced by social discourses and cannot be assumed to have "common sense meanings ... without critically reflecting on the cultural, historical, and social forces that produced those meanings" (Beres, 2007, p. 95). If we do operate on an assumption of shared meaning, she shows, gendered "miscommunications" happen, where a woman's behavior can be argued to be assumed to be consensual when she did not intend to be read as agreeing to sex. This, of course, is an example of objectification in action, justified by social assumptions as well as gendered entitlements to desire, sexual pleasure and other people's bodies. Accordingly, Beres (2007, p. 97) critiques studies that assume that consent is something given by women to men, which establishes a norm where, 
$[\mathrm{M}] \mathrm{en}$ are viewed as always desiring sex, and always in pursuit of sex. Through this discourse, men's consent is assumed, so to question it or develop an understanding of it would be superfluous. This places women in a position of responding to men's initiations, setting limits, and deciding if they want to participate in the sexual activity.

Thus, the active/passive gendered binary, based on a notion of sexuality as underwritten by biology, is still in play. Also evident is a false assertion of power given to women, as the ones who generate desire in men, who are less sexual than men and might not always be up for it, and who therefore control access to men's pleasure.

Beres (2007) also shows how different definitions enable consent to become "consent," when someone putatively consents because resistance seems futile, because they were drunk or for other reasons that complicate the definition of "unwanted sexual activity" under duress, which can still be read as consent under certain definitions (Beres, 2007, p. 96). Consent is not best conceptualized as something binary-where one person initiates activity and the other person then gives or refuses consent. Instead, in real time, initiation of activities can shift between partners. And of course, as Beres (2007) also acknowledges, the act of speaking, and especially speaking about something as personally and socially complicated as sex and sexual desire, is not freely done. It takes place within the context of gendered power dynamics. Even consensual sex can be "harmful" when "the consensual force is social, rather than interpersonal" (Beres, 2007, p. 99).

Social coercion, different from interpersonal coercion, cannot be dealt with legally, and is much harder to hold accountable for its harmful effects:

Consent becomes something broader than just a "yes" to sex with a specific person, in a particular place, at a particular time. It becomes a negotiation of social expectations, a way of expressing a social identity, or of fitting in to a certain social world. It creates spaces for sex that are neither consensual nor criminal or violent, although they may be socially problematic. (Beres, 2007, p. 99) 
Within a binary view of consent, there is no way to articulate the fact, or address the consequences, of what happens when women consent to sex they do not want. Thomas et al. (2017, p. 285) invented the phrase "gak sex" to try and indicate the variable experiences of violation and shifting desire that occurred under the rubric of unwanted sex that was apparently, in the heteronormative terms provided above, consented to. They eventually chose the moniker "problem sex" as more academically sound. They noticed that their study participants did not themselves have language to account for "problem sex," that is, sex that was undesired or bad or both, but which the women themselves did not identify as coerced, despite the use of hedging, disclaiming, minimizing, deflecting or qualifying when accounting for how they experienced their consenting (or not consenting). As a result, the authors tracked discursive attempts to make sense of the experiences in the face of a lack of language available to the women as they described their "unwanted sexual experiences," including experiences that the authors state can be "clearly identified" as rape, but were never described as such by the participants (Thomas et al., 2017, p. 287; see also Rutherford, 2018a). More often, the authors note, the young women in their study trailed off into silence after using negative formulations (it was bad sex, it was not good): "participants articulated what sex was not, however they struggled to find the language to communicate what it was" (Thomas et al., 2017, p. 292).

Young women (as is typical of the sampling used in much academic psychology research, the participants in Thomas et al.'s, 2017 study were undergraduates) are not always able to name sexual coercion when they experienced it. They have internalized the message that they are obliged to have sex, that consenting to sex they do not want or even, in some cases, that is consistently painful, is a normal part of heterosexual relationship management (the authors found that even while participants recounted experiences of sex without desire with other women, it was exclusively in the heterosexual encounters that they found the discursive complexities noted here). They are also not in possession of vocabulary for experiences where they felt unable to say no, or chose not to say no despite not wanting to have sex, but did not feel overtly coerced, at least not by their partners. They may well have been coerced by the rules of heteronormative binary gender in the twenty-first century, mediated as it 
is through thousands of years of pressure and more recently through neoliberal discourses of personal choice, postfeminism and entrepreneurial agency. It is worth noting, as we consider the WEIRD (white, educated, industrialized, rich, democratic) samples used in most of the consent studies, Young and Hegarty's (2019) calling out of the imbrication of sexual harassment as simultaneously the object of study and part of the culture of academic social psychology. They advocate, using literary metaphors, critical theory, biography and oral history, for a feminist methodology that challenges a "masculinist fantasy of unreflexive science" (Young \& Hegarty, 2019, p. 453), a project of the psychological humanities if ever there was one.

Also disturbing is the implicit picture of hordes of young men who either do not know or do not care that their partners, often long-term partners, are not enjoying their sexual encounters. This implication of the research done with college women helps illuminate Ward's (2020) work on the current state of the "seduction industry," which exploits twentyfirst century, feminist-derived discourses about respect and emotional intimacy to teach men how to manipulate women into the sex that these men continue to feel entitled to. Once again, these thoughts, feelings and behaviors can be understood as authorized by a binary view of gender, which makes men active subjects to the female objects they depend upon, and whose humanity, as Ward (2020) shows, they (therefore?) cannot tolerate.

Despite some cultural myths about "misunderstandings" between heterosexual partners resulting in experiences of sexual violation by women, the truth is much more complex (Beres et al., 2014), and has everything to do with binary gendered rules, the subjectivities they create and inform, and the gendered behaviors upheld by social norms and systems. The implications are relevant for all men, not just those who deliberately abuse their power. Most men need to learn to listen more honestly, to ask, to establish consent and desire, and also obviously to stop assuming that social, psychic and economic power entitles them to other people's bodies. There are also implications for women, who may find it very, very difficult to speak up in the complex system of power, sexuality and gendered selfhood within which they are trying to make a living, to make a personhood. Let me be clear: Most cases of sexual violence are not ambiguous. 
There are far too many "unacknowledged rape victims" (Peterson \& Muehlenhard, 2007, p. 74) as a direct result of the lack of vocabulary about the interactions of social rules for gender performances, internalized gender rules, consent, wanting and the complexities and shifting nature of desire. This is not to mention the unacknowledged rape survivors who are simply disbelieved or ignored despite their clear statements of having been overpowered and violated with no ambivalence on their part or the part of their attackers. There is no onus on women to prevent their violation. In the grayer areas also, consent must be established, not assumed. And this is the point: there clearly are gray areas, because of the rules of binary gender and the kind of heteronormativity they inscribe.

So it is not the outright violence I am working so hard to establish ways to talk about here. It's the everyday, systemic, complicitous, intertwined violence that is also part and parcel of normative binary gender. Since the MeToo movement made male abuse of power in the realm of sexuality more visible and easier to insist on, since the profound cultural disbelief women and girls and other feminized people have always had to survive has been somewhat challenged by the public speaking (finally!) of sheer weight of numbers, many more female or feminized people are starting to talk about what happens to them at the hands of the men in their lives.

One of the first feminists to insist on the wide-scale scope of the problem of gender and structural violence, in the terms of modern psychology, was Herman, in Trauma and Recovery (Herman, 1997). She insisted that if war is the arena where men are traumatized, the family is the gendered site of female traumatization (and the traumatization of children). Her book encompasses many sites of what was then, even more than now, socially sanctioned gendered abuse, in part because her work helped bring attention to how systemic gender violence works. In constructing this argument, Herman was arguing for refusing the construction of certain spheres of life as "private" and therefore unavailable to interrogation for the relations and operations of power. She also writes in detail, and with evidence, about the gendered forms trauma can take. In so doing, she explains the behavior of women traditionally cast as hysterical, and, more recently, as borderline. She details trauma symptomology long unrecognized; she interrogates ways of understanding-or, more 
accurately, the ways Western societies have persisted in not understanding - women's experiences of violence and violation at the hands of those they trust.

Thus, anticipating consent studies, Herman (1997, p. 65) explained why, "Because of entrenched norms of male entitlement, many women are accustomed to accommodating their partners' desires and subordinating their own, even in consensual sex." And, not surprisingly,

Many acts that women experience as terrorizing violations may not be regarded as such, even by those closest to them. Survivors are thus placed in the situation where they must choose between expressing their own point of view and remaining in connection with others. Under these circumstances, many women may have difficulty even naming their experience. (Herman, 1997, p. 67)

I want to make space to bring into focus the working of our inevitable complicities: not that victims are to blame, but that the rules of gender which make speaking up in intimate ways about our desires so damn difficult might be confounding of notions of female agency and of the value of female desire in heteronormative heterosexuality, and certainly in the rape culture that exists in tandem with it. Some women are not asked. Some women say no and are ignored. Some women do not say no but do not consent. Some women endure really, really bad sexual experiences, where they are used as objects, disregarded, where their desire is not honored or even expected. These are all part of rape culture, they are all damaging, and they are all unacceptable. They are not all sexual assault.

I know how easily this can be read as victim-blaming, as excusing men at best careless and at worst brutal, as missing entirely the point that not everyone has equal access to voice in systems of power. I hope the more subtle point emerges: We must find ways to resist that inhabit the complicit intersection of the personal and the systemic, that seek to clear the internal air of the social smog that teaches us we have to comply. This is in addition to, not instead of, naming criminal behavior, holding men accountable and putting the shame of violation where it belongs, on the violator. 
We would be better off engaging in much more depth with rape culture as a structural formation within which binary heteronormative gender takes its shape. We would also be well-served by avoiding simplifying what are gray areas that arise in moments of intimacy because of the internalized injunctions of normative gender. Really, opening gender up beyond the binary will help everyone with this problem.

As we have seen, Thomas et al. (2017) identify that the young women in their study all fake pleasure and/or orgasm in order to end unwanted sexual encounters. They found that this strategy was used both to end unsatisfying sex and to end sex that was either unwanted or was painful. They recount an instance when the interviewer engages with this choice with one of the participants:

[I]n another section of the interview with $\mathrm{X}$, the interviewer prompted her to consider ending sex without faking orgasm:

$\mathrm{X}$ : For me, like I said, the end result was just, let's get this over with and the fastest way I can get this over with is t- for him to think that I had an orgasm? So he'll have one? And we can be done. Um::

I: Right. To play the devil's advocate for a second, a fast way- a faster way would be to say, yeah, no, let's:-

X: Yea:::h hhh. I guess so... . I do- I don't know if I could just stop mid(hh)w(hh)ay thro(hh)ugh, I re(hh)ally do(hh)n't.

I: Yeah

X: I think that would just be, almost too awkward? Like, at least if you can-if he can finish, then you can just get up and leave and kinda go do whatever you have to do, or: whatever, whereas... if ya did just sorta stop part way through and say, "you know what? This isn't working, and I'm do::ne?"

I: Right

$\mathrm{X}$ : I think that's gonna lead into a discussion that maybe necessarily I don't wanna ha::ve::? Or:::. I don't know, I guess I take the easy way out? If that-pardon the pun, but, um:.

I: ((laughing))

X: It, uh. Yeah, to just sorta—-to help him finish? Means that I could just walk away.

As indicated by X's response, the interviewer's suggestion that she could end sex directly appears inconceivable. (Thomas et al., 2017, p. 294) 
What is going on with heterosexuality when a discussion about mutual desire and pleasure is too much trouble? How is this young woman experiencing her embodiment, her intimate connections? Her selfhood? Her body becomes a tool she herself uses to maintain these gendered relations. The authors note the women's assumptions that "heterosex must and will end with male orgasm... In this way, women's ability to express the desire to end a sexual encounter outside of this prescribed 'ending' is effectively restrained both discursively as well as materially" (Thomas et al., 2017, p. 295).

Yes, this young woman is constrained, by a host of forces beyond her control, including a paucity of language for her to make different sense for herself of what is happening within and to her. Rutherford (2018b) offers a comprehensive critique of how the discourse of empowerment acts on young white women under neoliberalism to compel them to feel they can choose as individuals, while denying structural factors that may be constraining them or acting on their senses of self. And the young woman in Thomas et al.'s (2017) study is also exercising a choice, however limited. She has some agency, and she uses it complicitously. This is not a criticism. It is an acknowledgment of how we survive the systems that shape us within a culture where race, gender and other markers of difference from a mythical norm are used to keep us in our assigned places. Here is an example of complicity in action:

Faking orgasm can be regarded as a form of "embodied hedging" as it avoids the consequences that may come from a direct refusal to sex all the while allowing the woman to determine when the sexual encounter ends. Thus, we argue that feigning sexual pleasure is both problematic and helpful at the same time. (Thomas et al., 2017, p. 296)

The authors note that faking orgasm when there is a risk of violence is a necessary use of a normative heterosexual script, designed to mollify the man while protecting oneself from further harm. Therefore, "we are calling to puncture the established parameters of heterosex for a social reconceptualization that acknowledges, names and confronts the problems women spoke of in our interviews" (Thomas et al., 2017, p. 296). These problems cohere around the missing discourses of pleasure for the women 
in the study, and the apparent use of their sexual agency to make their male partners happy at the expense of their own physical and/or psychological wellbeing. The paucity of language for describing the nuances here is telling of the power dynamics at play in the system of binary gender, and the material realities they enable:

When wanted and consensual yet disappointing/unsatisfying, sex is talked about in the same manner as experiences of unwanted and/or coercive sex and sexual assault, unwanted experiences may be at risk of being passed off as simply not pleasurable. Within dominant constructions of sexual assault, which dichotomize sex as either consensual and wanted or nonconsensual and unwanted (rape), all other experiences that do not meet either definition may be dismissed as "just (bad) sex". (Thomas et al., 2017, p. 296)

The authors conclude that the real solution is in moving beyond the "existing limiting and dichotomous conceptualizations of heterosex" (Thomas et al., 2017, 297). In other words: the binary.

Endorsing the terms of the consent studies addressed here, Ward (2020) details how one of the aspects of straight culture has always been men's sense of entitlement to women's bodies and to their emotional labor. She shows how binary-formulated heterosexuality repeatedly puts the onus on women to do the work of managing this dynamic. It also leaves men hurt and angry when it fails to deliver. Ward (2020, pp. 114-5) writes of,

[T] he seemingly inextricable place of sexual coercion and gender injustice within straight culture... the violence and disappointments of straight culture... (the bad and coercive sex, the normalized inequalities of daily life, straight men's fragility and egomania, straight women's growing disillusionment with men's fragility and egomania, the failed marriages, the coparenting that is really solo parenting...)

One thing remains clear: The toxic rules of binary gender need to change. As much as social and political progress has been made for some women, cultural gender norms continue to structure psyches and relationships in damaging ways. 
I have not spoken here about masculinities, but it is very much to the point that men are also limited and defined by, as much as they profit from, normative gender and the power relations it encodes. Beres (2007) points out that one example of a consequence of compulsory heterosexuality is to make a man who would like to be sexually involved only with other men, have sex with women. Ward (2020) shows how dependent heterosexual men are on acceptance from particular kinds of women, who carry the projections of their masculine self-worth.

Ward (2020, p. 155) looks forward to what she calls "deep heterosexuality," which is, essentially heterosexuality without heteronormativity. It is a way for people to relate intimately without their identities being structured by the complementarity of binary gender norms which, as Ward (2020) shows, means that what she calls straight culture begins with the paradox that men desire women they cannot like or respect as equals.

\section{Transnational Lessons}

The involvement of well-intentioned Western queers (as this formulation suggests, structurally in the position of well-intentioned whites discussed in Chap. 2) in matters of African sexual and gender rights can cause active harm (Epprecht, 2013; see also Hayes, 2001). For example, Epprecht (2013, p. 13) details the damage done by "homonationalism," which "means taking excessive pride in the achievements of gay rights activism in the West and showing chauvinistic regard for the Western model of outness." This overlooks that for some subjectivities, experiences of individual teleological development are not culturally appropriate or relevant. It also overlooks the complexities of social, cultural and legal strictures that many people outside of the West must navigate, as will be explored in more detail below. As a result, the use of Western LGBTQ processes and terminology for understanding African sexualities remains complicated, something "Africans and Africanists who do gender and sexuality research remain extremely reluctant to embrace... even when they make use of insights from the queer canon" (Epprecht, 2008, p. 14). At the same time, as Hawley (2001, p. 12) also acknowledges, "the 
'universalizing' of gay terminology (condemned... as hegemonically Western) in fact can serve a local liberatory function." International human rights discourses and instruments rely on Western models of personhood and of Western legal norms, and can be helpful to some subjects in non-Western contexts even as they also interfere in local formations and overlook or inadvertently harm others. This, too, will be explored below. The construction, Western LGBTQ discourse helpful to Africa/ Western LGBTQ discourse harmful to Africa, is an inaccurate binary. I hope to illustrate that on an entangled transnational level, colonial history has created its own forms of complicity, in this case in the realms of gender and sexuality. It is worth noting here, and this will be returned to below, that gender and sexuality are connected in many African places in a way they are no longer in Western LGBTQ+ discourse. This, too, creates difficulties in using Western terms to articulate some African experiences.

There is another way that Western frames are not helpful to the issue of sexuality justice in Africa. In 2016, I attended the annual conference of the American Association of Marriage and Family Therapists, the national umbrella body for my profession. One of the keynote speakers was talking about the psychological effects of homophobia on LGBTQ individuals, and to illustrate some of his points, he showed us a video he found on the internet of homophobia at work. In Nigeria. We saw a concerned white male American journalist interviewing abject black men, who spoke about their homosexual identification and the oppression they suffered accordingly. African conservatism, ignorance and dictatorial violence were set off against the West's enlightened, modern, accepting views. Because, you know, there is no homophobia in America, and Africa is by definition premodern. Epprecht (2013, p. 10) tracks some of the ways that unwitting [promotion of] stereotypes of " Darkest Africa'homophobic, violent, irrational... fundamentalist” only increases backlash against Western interference, as does the narratives of "those who would have us believe that nothing in Africa happens unless inspired by the West." When I challenged the speaker on his decision to pick a depiction of brutal African suppression of same sex love in order to illustrate the psychological effects of homophobia on gay-identified people, he replied that he had merely surfed the internet for illustrations of 
homophobia to give at his talk, and that that the choice of Nigeria was random. Considering this was a plenary on the effects of culture on oppression, I found this an extraordinary response, and one that underscored an American tendency to forget that Africa is a complex collage of multiple cultures with different histories and dynamics, and a relation of power to the global system. Nigerian men articulating Western identities for American cameras as they fight for their lives is not a straightforward proposition, and certainly not an appropriate illustration of Americanderived theories of the psychological consequences of homophobia for Western subjects.

Like many other Africans, although inflected differently by the country's ideological location on the continent due to South Africa's in-theory legal protections, same-sex loving South Africans and South African people who identify as genders other than the ones they were assigned at birth have to engage with the inheritances of colonialism as they live their nonnormative lives. As Desai (2001, p. 156) puts it,

The question at this point... is not whether or not indigenous alternative sexual practices have existed or continue to exist in Africa, but rather, how one understands their historical emergence, the conditions of (im)possibility for identity formations based on these practices and in particular the relationship of these identities to racial and national identities.

The notion of "(im)possibilities for identity formation" in neocolonial, postapartheid South Africa sums it up nicely. People are expressing themselves and their sexual and gender identifications using, variously, exclusively or in combination, Western LGBTQ discourses and traditional and indigenous frames. They are using and changing what the West has brought. They are doing this in the face of African patriarchies that want to invoke versions of tradition to enforce heteronormativity, and that want to scapegoat African gender and sexual queers for the profit of national identification and politics. These constructs of authentic tradition, of modern nationhood and of heteronormativity are, of course, products of colonial history.

In order to untangle the complicities at work here, we have to see how people navigate developing personal understandings of the relationship 
between sex and gender, sometimes within versions of traditional culture as they are currently lived in neocolonial forms, instantiating the conditions and possibilities of late modernity, and dealing with postapartheid nationalism, which continues to be in ambivalent relation to the country's inclusive and protective Constitution (Epprecht, 2013; Munro, 2012; Sideris, 2005; Van Zyl, 2009). As Trengrove-Jones puts it in 2008, in response to yet another murder of women identified as lesbians, "To inhabit an 'alternative sexuality' in South Africa at the moment is to be a raw receptor for the clash of cultures currently underway" (p. 182).

So-called gay rights (so-called because the moniker "gay" is too narrow to accommodate all the identities and practices-without-Western-identities that are affected by this issue) is the place where postapartheid South Africa's newness and nondiscrimination commitments symbolically emerge, and it is a high-profile place where a conversation about decolonialism can be abused. It is one place where discourses of authenticity and purity become so dangerous and invested. Munro (2012, p. xiii) comments, "Homosexuality in Africa is bound up with a contradictory modernity that has been produced both within and against imperialism, and this is what makes the question of gay rights in Africa so politically fraught." As a local informant reported in a recent Economist article on the struggle for women's land rights in the context of postapartheid compromises with the traditional authorities used by both colonial and apartheid regimes, "If you want to resist change, it makes sense to pretend it undermines your culture" (“Trust deficit”, 2020, p. 74).

These issues arose with the passage of the 2006 Civil Union Act in South Africa, which granted marriage rights to those who were intelligible to the Westernized legal system. Those same-sex-loving South Africans, often not in the metropolitan areas or not empowered to speak up in opposition to community pressure, who were to some extent or another queer-acting or queer-identified, were even more marginalized: The ship of gay rights had sailed, and they were not on board. Additionally, this situation crystallized a binary where modernity and civil protections are set up in opposition to more traditional African or Islamic cultural formations, which are then cast as by definition benighted (see Bilchitz \& Judge, 2008; Bonthuys, 2008). The debates generated by this Act, about gay rights and about the new legal protections afforded women and 
sexual minorities in the country, were complex affairs of assertions of cultural authenticity, misogyny and homophobia, and neocolonial decolonial articulations (Reid, 2008).

Discourses that come from the West, even though-or because-they provide scope for changes to the current cultural and political systems to better accommodate some Africans whose sexuality appears "modern" (i.e., not "traditional"), also are available, by virtue of their origins, as ammunition for certain African leaders who are looking for smokescreens and decoys. Some invoke a neocolonial version of tribal law, which has passed through Christianity and also through Western political corruption to emerge abusively heteronormative and patriarchal, all in the name of an imagined authentically precolonial Africanness. Zimbabwe's Robert Mugabe, Uganda's Yoweri Museveni, Gambia’s Yahya Jammeh, Nigeria’s Goodluck Jonathan, to name some, have at various points over the past decade contended that homosexuality is unAfrican, a Western import, a colonial disease. Contradictorily, they sometimes invoke that other Western import, Christianity, to deny the authentic Africanness of homosexual desire. Since the identity position "homosexual" was invented in the West, to some extent they are correct. Nevertheless, those same-sexidentified Africans who identify as LGBQ or $\mathrm{T}$ in Western terms are surely no less African for doing so. But even without these terms, samesex sexuality has always been part of African cultures.

Same-sex-loving Africans have always existed, and in fact, same-sexoriented sexuality was woven into the fabric of precolonial African societies across the continent (Epprecht, 2004; Epprecht, 2008). Before colonialism, there were ways for same-sex-loving Africans to live within their societies undisturbed. In part, this was because their practices were not necessarily an identification and did not threaten the social structure.

So, for example, in Southern Africa alone, there are several social forms that facilitated same-sex intimacy in terms that utilize, and exist alongside, heteronormativity. These include the relationships among adolescent girls in Basotho, Venda and Zulu societies studied in the 1970s sometimes as "mummy-baby" friendships which involved both kinship and sexual relations (Wieringa, 2005). These relationships were seen as healthy forms of emotional connection as well as good preparation for heterosexual marriage. Part of the acceptance of same-sex female erotic 
interaction was, and remains, the idea that nonpenetrative sexual activity is not sex.

So-called mine marriages were a complex institution between men emerging from colonial and apartheid economic practices. Men would contract relationships with each other on highly gendered terms. The authentically homosexual emotional and sexual components of these relationships have been articulated, in opposition to the frame of purely situational homosexuality (By Zachie Achmat, Hugh McLean and Linda Ngcobo, and William Spurlin, e.g.; see Spurlin, 2010).

In addition, traditionally, marriage between women was not an uncommon practice in Southern Africa and elsewhere on the continent, before the missionaries arrived. A woman could take the structural position of a man, either in her own right or in the name of a deceased male relative. What was important was that the female husband could afford to pay for her wife, and that they used a man to help them have children, thus fulfilling their commitment as a couple to the social order (Morgan \& Wieringa, 2005).

None of this is queer in the Western sense-none of it seeks to defy categories or to demand new cultural spaces for people to self-define. People engaged in these activities mostly did not intend to challenge the dominant terms or power structures. They did not, and do not, require a discourse of coming out, or self-discovery, or an oppositional placement to one's family or community. At the same time, these practices allowed people to have the space to live alternate sexual lives, in practice if not in identification.

And this history feeds into African queernesses that have emerged post colonialism and the neoliberal order it birthed, which gives some Africans access to Western modes. In South Africa today, an increasingly vocal constituency are the lesbian sangomas, whose sexual decisions are made through the proxies of the male ancestors they represent. As powerful spiritual leaders, they have a place within African traditions from which to assert their own legitimacy. Nkunzi Nkabinde was perhaps the most well-known South African lesbian sangoma, who at the time of her/his death in 2018 appeared to be exploring a gender transition; they published an autobiography (Nkabinde, 2009), as well as engaged in documentary work with others in their community. 
Their writing shows that same-sex-loving female sangomas do not all identify, as Nkabinde did, at least for a time, as lesbian. Some speak a language that sounds to Western ears transgender, some hold a dual and unconflicted identity as what we might call bisexual and some identify as female men (see also Letsike, 2011; Morgan \& Wieringa, 2005). This is not to suggest that the process is easy. Many of them are survivors of sexual violence and discrimination prior to and during their sangoma training processes, and some continue to be secretively sexually involved with their wives because of the stigma associated with LGBT identities in many communities. The violence they face is both on account of gender and of sexuality, as sexual violence rates are hideously high in South Africa, with same-sex-loving women being a specific targeted group (Gqola, 2015; Muholi, 2011).

Epprecht (2008) has demonstrated the ways in which traditional African social structures were disturbed by colonial rulers, missionaries and early anthropologists, who brought their Western disdain of samesex practices to the African colonies at around the time that homosexual practices were crystallizing into homosexual identities in European discourses. As was typical of colonial processes of binary meaning-making, Western observers constructed a sense of their own superiority and rightness by relying on the putative barbarism of the cultures they encountered, and could thus be called upon to civilize. Among other things, this dynamic set up an imperative to silence on the part of Africans who were adjusting to the new order, which helped to create what Epprecht (2008, pp. 34-64) has succinctly designated an "Ethnography of African Straightness."

In addition, Western colonizers brought with them to Africa their construction of African sexuality as unbridled (Epprecht, 2008). This racist discourse relied also on a vicious misogyny, legitimized by Enlightenment science, as the case of Sara Baartman has made so clear (Crais \& Scully, 2009). In life and death, Baartman's black female body was made to stand for all that was denied in nineteenth century Europe's picture of itself: exotic, hypersexual, available for consumption (see Perry, 2018). And if Africans were hypersexual, it was because they were hyper heterosexual. This Western imperative- that blackness carry the West's stigma about sexuality—intersected with another Western discourse of Otherness, to 
enable homosexuality to be "given" to the Orient, as its particular form of effeminized, luxurious inferiority. Africanness was by definition heterosexual, according to the West (Epprecht, 2008).

So, if homosexuality as a modern identity exists in Africa because of colonial history, so does homophobia (see Epprecht, 2004). And ironically, tragically, when those African patriarchs make use of homophobia to encode a version of the postcolonial African nation designed to funnel power to themselves, by constructing a logic for who can be in and who can be out, who can be controlled according to the old rules and who must be purged, they are profiting from a discourse that is as fundamentally racist as it is heteronormative. As we have seen, the connection between racism and heteronormative homophobia has its own history in America, too (Carter, 2007; Ward, 2020).

In contemporary Western discourse, there is a difference between transgender people and sexual queers: gay, lesbian, bisexual, asexual, same-sex loving and other people whose sexuality is nonheteronormative. Transgender identity is about gender, not sexuality. But trans people and queer people are often considered together, since all of those categories in some way disrupt the constitutive relationships between binary gender, heteronormativity, cisnormativity and the assumptions about bodies and identities they enable as complementary. All this should be familiar by now. In a South African context, the relationship between genders and sexualities is harder to articulate through a Western frame. Colonization brought political and social oppression, Christianity and bourgeois values. It set up a version of tradition which has affected postcolonial national identity politics. These histories intersect with pre-existing local expressions and enactments of alternative sexualities and gender identities. The result, in the context of decolonial imperatives to reject Western epistemologies and allow for the emergence of local ones, is, in this arena, a set of "contradictory tensions that seem to suffuse issues of gender in relation to sexuality" in Africa (Camminga, 2019, p. 18).

In South Africa, binary gender positions are sometimes invoked in service of queerness, so that same-sex relationships are expressed through male and female roles and identities, in ways which confound Western identifications, allowing, for example, straight men to be in relationships with men who identify as taking the female position because of their 
sexuality, but who are not trans (Reid, 2005). Some of these ladies might identify as trans, given the option, but many may not need these kinds of categories to be who they are within the terms available to them. Camminga (2019) explores the case of two people from Malawi who, from their own identifications, seem to be what Western classifications would call a heterosexual man and a transgender woman, but who were received as gay men for the purposes of drawing attention to their persecution and for the purposes of acquiring asylum, in the case of the woman (see also Epprecht, 2013). This is in part because of the lack of official recognition of Western-type transgender identities to date in the South African asylum application process.

Camminga (2019) traces how transgender as an identity travelled in specific ways to and in southern Africa. They trace the advent of what they, following Stryker (2008), call transgender phenomena in South Africa as a specific site, given its history and given its postapartheid Constitution, which uniquely in Africa protects the rights of gender and sexual minorities, as well as refugees to the country. Part of their project explores the relationship between classifications of sex and gender, imported from the West, and state mechanisms which enable national belonging; as well as the journeys toward an imagined home that are implicit in many conceptualizations of transgender, as well as in being a refugee.

Camminga's project demonstrates the ongoing conflation of transgender presentations with homosexuality, as well as the complexities of assigning a Western-developed discourse and/or the identities developed therein, to other cultural contexts, particularly given colonial histories. They conclude that because of its postapartheid legal instruments, as well as the way that transgender as a category and an identity evolved in South Africa in complex relation to both local LGB and international discourses, "South Africa represents... a space which suggests that one's orientation in terms of desire and the shape of one's body might be supported without necessarily having to use a specific discourse" (Camminga, 2019, p. 111). Transgender as a label and an identity continues to be emergent in South Africa and may always be in both dialogue and dispute with Western categorization. 
And things continue to change. In 2020, a year after the publication of Camminga's book, the Professional Association for Transgender Health South Africa (PATHSA) was formed, "an interdisciplinary health professional organization working to promote the health, wellbeing and selfactualization of trans and gender diverse people" (pathsa.org.za). PATHSA presented itself to the international association of multidisciplinary transgender health healthcare workers, WPATH, in November 2020 at the online WPATH conference. It is the first South African organization of its kind, and joins Gender DynamiX, formed in 2005 (genderdynamix.org.za), as one of the very few specifically gender-focused groups in the country. Anecdotally, one of the first struggles faced by this organization is engaging with homophobic discourses authorized by a version of Christianity and the understanding it brings to the way transgender people are seen.

The Anglican Church has around 77 million members. Over 30 million of these are African (Hoad, 2007). This is, of course, thanks to colonialism. But if millions of Africans are now devout Christians of whatever denomination, including versions that blend Western modes with African ones, then Christianity surely is as African as honoring the ancestors. As Hoad (2007) details, at the third Lambeth Conference, held in 1888 when Europe was still dominating Africa in colonial terms, the bishops passed two resolutions on polygyny. The one, which applied to men, decreed that even a polygynist who converted to Christianity could not be baptized until he accepted monogamy. The other decreed that his wives could be baptized "under conditions to be decided on locally" (Hoad, 2007, p. 50). Hoad argues that if, in 1888, "[cis]gender carried the weight of cultural difference" in the Anglican Church's attempts to engage with its African constituents, then a century later, "homosexuality hands this task over to sexuality" (Hoad, 2007, p. 52). This is seen in his exploration of the complexities of Western class and sexual norms at work in twentieth-century Africa, at the World Conference of Anglican Bishops that took place in Lambeth in 1998.

In 1888, the bishops in Africa were all British missionaries. In 1998, the by-now international body of bishops had a more tolerant attitude to polygyny, and an unaccepting view of homosexual Africans. Noncelibate homosexual clergy and the officiating of same-sex unions, issues in part 
forced by the emergence of gay rights as a constitutional principle in postapartheid South Africa, were issues on the Lambeth agenda for the first time. The African bishops, with the exception of some from South Africa, unanimously argued that homosexuality was unchristian and unAfrican, and threatened to break ties with their European colleagues over the matter. Hoad (2007, p. 56) comments:

Why do African bishops pledge allegiance to a literal interpretation of Scripture with the attendant... wholesale disavowal of the possibility of indigenous same-sex practices?

He goes on to suggest that attacks on homosexuality, because it is seen to be specifically Western, is one way to repudiate the construction and imbrication of African barbarity and sexual incontinence. African bishops can assert their respectability in the face of centuries of racist stereotyping of Africans, and in the terms given them by the racist West, by being the best homophobes possible. The ironies are painful, and they multiply when we remember that the tolerance of homosexuality is often constructed by developed nations as a sign of advanced civilized values, in opposition to more "traditional" — read developmentally impaired or teleologically backward-cultures.

The realm of sexuality becomes a place where the moral high ground can intersect with deep historical wounding. "Homosexuality" comes to stand for a nexus of meanings that encode contested definitions of civility. It also comes to be a frame through which to understand nonnormative genders, including transgender identification. Not surprisingly, sexual morality affects everyone's gender roles, and the version of the authentically African nation which seeks to purge its homosexuals tends to rely equally upon a version of heterosexual domesticity which needs women to stay in their proper domestic place, often revered as symbols of Mother Africa, the nurturer, the home-maker for the children. This version of bourgeois respectability is precisely the one that was used against tribalized Africans when the civilizing mission began (Epprecht, 2008). It is now being used by some Africans against African women and queers. The postcolonial African nation is, (im)possibly, formed by modernity and authorized by an invested notion of tradition. The nexus of this contradiction is 
the figure of the African homosexual, sometimes also transgender, and his or her repressed shadow is the "traditional" same-sex-loving African.

Violent homophobia continues to be an urgent problem in South Africa. Combined with misogyny and HIV, its expressions can be lethal. Photographer and activist Zanele Muholi has created an incredible archive which speaks to the emergence of indigenously queer communities and all they continue to endure, despite one of the most progressive Constitutions in the world. Muholi's own identity journey marks a fluidity in queer/African/nonbinary process, always centered in their race, place and nationality (Muholi, 2011; Muholi, 2018). If this is not a lesson in what binary identifications leave out, I don't know what is.

We need to problematize the ease with which African homophobia is available to underwrite the work of a Western LGBTQ politics and political identity. There is no modern/traditional binary in practice. What we are left with is the impossibility of a neat binary of us and them, of right and wrong, of good and bad. I do not mean by this to deny the effects of oppression, to suggest that the workings of power on the bodies of queers, of women, of Black people, is in any way ambiguous or excusable. Instead, I want to surface the complexities of doing something about it-the necessity of holding our locations in time and place, and of owning the messy and complicit histories that have made us all, in relation to each other.

\section{Works Cited}

Atienza-Macías, E. (2020). Some reflections on transsexuality in the New International Classification of Diseases (ICD 11): A product of the World Health Organization (WHO). Sexuality \& Culture, 24, 2230-2235.

Aughterson, K. (Ed.). (1998). The English renaissance: An anthology of sources and documents. Routledge.

Azul, D. (2018). Trans-speaking voice-lessness: A fictocritical essay. Graduate Journal of Social Science, 14(2), 107-134.

Bay-Chen, L. Y., \& Bruns, A. E. (2016). Yes, but: Young women's views of unwanted sex at the intersection of gender and class. Psychology of Women Quarterly, 40(4), 504-517. 
Beecher, D. (2005). Concerning sex changes: The cultural significance of a renaissance medical polemic. Sixteenth Century Journal, 36(4), 991-1016.

Benjamin, J. (1988). The bonds of love: Psychoanalysis, feminism and the problem of domination. Random House.

Beres, M. A. (2007). "Spontaneous" sexual consent: An analysis of sexual consent literature. Feminism \& Psychology, 17(1), 93-108.

Beres, M. A., Senn, C. Y., \& McCaw, J. (2014). Navigating ambivalence: How heterosexual young adults make sense of desire differences. Journal of Sex Research, 51(7), 765-776.

Berry, P. (1989). Of chastity and power: Elizabethan literature and the unmarried queen. Routledge.

Bettcher, T. M. (2014). Trapped in the wrong theory: Rethinking trans oppression and resistance. Signs: Journal of Women in Culture and Society, 39(2), 383-406.

Bhabha, H. (1994). The location of culture. Routledge.

Bilchitz, D., \& Judge, M. (2008). The Civil Union Act: Messy compromise or giant leap forward? In M. Judge, A. Manion, \& S. de Waal (Eds.), To have \& to hold: The making of same-sex marriage in South Africa (pp. 149-163). Fanele.

Boose, L. E. (1991). Scolding brides and bridling scolds: Taming the woman's unruly member. Shakespeare Quarterly, 42, 179-213.

Bonthuys, E. (2008). The Civil Union Act: more of the same. In M. Judge, A. Manions \& S. de Waal (Eds.), To have \& to hold: the making of same-sex marriage in South Africa (pp. 171-179). Cape Town: Fanele.

Bornstein, K. (1995). Gender outlaw: On men, women, and the rest of us. Vintage. brown, a.m. (2020). We will not cancel us: and other dreams of transformative justice. AK Press.

Brownmiller, S. (2007). Against our will: Men, women and rape. In E. Freedman (Ed.), The essential feminist reader (pp. 311-317). Modern.

Bryant, K. (2006). Making gender identity disorder of childhood: Historical lessons for contemporary debates. Sexuality Research and Social Policy, 3(3), 23-39.

Buckner, R. (2016). Whose bodies count? How experience working with transgender patients shapes conceptualizations of transgender identity. Critical Theory and Social Justice, 6, 52-92.

Butler, J. (1993). Bodies that matter: On the discursive limits of "sex". Routledge.

Butler, J. (1999). Gender trouble: Feminism and the subversion of identity. Routledge.

Butler, J. (2004). Undoing gender. Routledge. 
Califa, P. (1997). Sex changes: The politics of transgenderism. Cleis.

Camminga, B. (2019). Transgender refugees and the imagined South Africa: Bodies over borders and borders over bodies. Palgrave Macmillan.

Carter, J. (2007). The heart of whiteness: Normal sexuality and race in America. Duke University Press.

Chowdhury, N., \& Gibson, K. (2019). This is (still) a man's world: Young professional women's identity struggles in gendered workplaces. Feminism \& Psychology, 29(4), 475-493.

Coole, D. (1988). Women in political theory: From ancient misogyny to contemporary feminism. Lynne Reinner.

Cooper, B. (2018). Eloquent rage: A black feminist discovers her superpower. Picador. Crais, C., \& Scully, P. (2009). Sara Baartman and the Hottentot Venus: A ghost story and a biography. Princeton University Press.

Cruz, A. (2016). The color of kink: Black women, BDSM, and pornography. New York University Press.

De Bloch, A., \& Adriaens, P. R. (2013). Pathologizing sexual deviance: A history. Journal of Sex Research, 50(3-4), 276-298.

De Lauretis, T. (1987). Technologies of gender: Essays on theory, film, and fiction. Indiana University Press.

Dean, T., \& Lane, C. (Eds.). (2001). Homosexuality \& psychoanalysis. University of Chicago Press.

Denny, D. (2004). Changing models of transsexualism. Journal of Jay and Lesbian Psychotherapy, 8(1-2), 25-40.

Desai, G. (2001). Out in Africa. In J. C. Hawley (Ed.), Post-colonial, queer: Theoretical intersections (pp. 139-164). SUNY Press.

DiAngelo, R. (2018). White fragility: Why it's so hard for white people to talk about racism. Beacon.

Distiller, N. (2008). Desire and gender in the sonnet tradition. Palgrave Macmillan.

Distiller, N. (2011). Fixing gender: Lesbian mothers and the Oedipus Complex. Fairleigh Dickinson University Press.

Distiller, N. (2012). Shakespeare and the coconuts. Wits University Press.

Doan, P. L. (2010). The tyranny of gendered spaces - Reflections from beyond the gender dichotomy. Gender, Place and Culture, 17(5), 635-654.

Dobbs, D. (1996). Family matters: Aristotle's appreciation of women and the plural structure of society. American Political Science Review, 90(1), 74-89.

Drescher, J. (2015a). Out of the DSM: Depathologizing homosexuality. Behavioral Sciences, 5(4), 565-575.

Drescher, J. (2015b). Queer diagnoses revisited: The past and future of homosexuality and gender diagnoses in DSM and ICD. International Review of Psychiatry, 27(5), 386-395. 
Drummond, J. D., \& Brotman, S. (2014). Intersecting and embodied identities: A Queer woman's experience of disability and sexuality. Sexuality and Disability, 32, 533-549.

Epprecht, M. (2004). Hungochani: The history of a dissident sexuality in southern Africa. McGill-Queen's University Press.

Epprecht, M. (2008). Heterosexual Africa? The history of an idea from the age of exploration to the age of AIDS. Ohio University Press.

Epprecht, M. (2013). Sexuality and social justice in Africa: Rethinking homophobia and forging resistance. Zed.

Erickson-Schroth, L. (2013). Update on the biology of transgender identity. Journal of Gay \& Lesbian Mental Health, 17, 150-174.

Ettner, R., Monstrey, S., \& Evan Eyler, A. (Eds). (2007). Principles of transgender medicine and surgery. New York: Haworth Press.

Faludi, S. (2006). Backlash: The undeclared war on American women. Broadway. Fausto-Sterling, A. (1992). Myths of gender: biological theories about women and men (2nd ed.). Basic.

Fausto-Sterling, A. (1993). The five sexes: Why male and female are not enough. The Sciences, 33(2), 20-25.

Fausto-Sterling, A. (2000). Sexing the body. Basic.

Feinberg, L. (1993). Stone butch blues. Firebrand.

Fine, C. (2014). Delusions of gender: How our minds, society, and neurosexism create difference. Norton.

Fisher, J. A. (Ed.). (2011). Gender and the science of difference. Rutgers University Press.

Freud, S. (1973 [1905]). Three essays on the theory of sexuality. In S. Freud, ed., The standard edition of the complete psychological works of Sigmund Freud, Vol. 7: A case history of hysteria, three essays on sexuality and other works (pp. 125-245). Trans. and ed. James Strachey, in collaboration with Anna Freud, assisted by Alix Strachey and Alan Tyson. London: Hogarth Press \& The Institute of Psycho-Analysis.

Garber, M. (2005). The return to biology. In I. Morland \& A. Willox (Eds.), Queer theory (pp. 54-69). Palgrave.

Gattuso, R. (2016). What I would have said to you last night had you not cum and then fallen asleep. Feministing, August 4. Retrieved December 22, 2020, from http://feministing.com/2016/01/19/what-i-would-have-said-to-youlast-night-had-you-not-cum-and-then-fallen-asleep/

Gavey, N. (2019). Just sex? The cultural scaffolding of rape culture (2nd ed.). Routledge. 
Gay, R. (Ed.). (2018). Not that bad: Dispatches from rape culture. HarperCollins. Gill, R., \& Orgad, S. S. (2018). The amazing bounce-backable woman: Resilience and the psychological turn in neoliberalism. Sociological Research Online. https://doi.org/10.1177/1360780418769673

Gilmore, D. D. (2001). Misogyny: The male malady. University of Pennsylvania Press.

Gqola, P. (2015). Rape: A South African nightmare. Jacana.

Grant, J. M., Mottet, L. A., Tanis, J., Harrison, J., Herman, J. L., \& Keisling, M. (2011). Injustice at every turn: A report of the national transgender discrimination survey report. National Center for Transgender Equality and National Gay and Lesbian Taskforce. Retrieved May 22, 2018, from https://www. ncgs.org/research/database/injustice-at-every-turn-a-report-ofthe-national-transgender-discrimination-survey/

Haraway, D. (1989). Primate visions: Gender, race and nature in the world of modern science. Routledge.

Harris, A. (2009). Gender as soft assembly. Routledge.

Hawley, J. C. (2001). Introduction. In J. C. Hawley (Ed.), Post-colonial, queer: Theoretical intersections (pp. 1-18). SUNY Press.

Hayes, J. (2001). Queer resistance to (neo-)colonialism in Algeria. In J. C. Hawley (Ed.), Post-colonial, queer: Theoretical intersections (pp. 79-98). SUNY Press.

Herman, J. (1997). Trauma and recovery: The aftermath of violence - From domestic abuse to political terror. Basic.

Hidalgo, M., Ehrensaft, D., Tishelman, A. C., Clark, L. F., Garofalo, R., Rosenthal, S. M., Spack, N. P., \& Olson, J. (2013). The gender affirmative model: What we know and what we aim to learn. Human Development, 56, 285-290.

Hoad, N. (2007). African intimacies: Race, homosexuality, and globalization. University of Minnesota Press.

Jones, A. R. (1986). Surprising fame: Renaissance gender ideologies and women's lyric. In N. K. Miller (Ed.), The poetics of gender (pp. 74-95). Columbia University Press.

Katz, J. N. (2007). The invention of heterosexuality. University of Chicago Press. Keo-Meier, C., \& Ehrensaft, D. (Eds.). (2018). The gender affirmative model: An interdisciplinary approach to supporting transgender and gender expansive children. American Psychological Association.

Langer, S. J. (2019). Theorizing transgender identity for clinical practice: A new model for understanding gender. Jessica Kingsley.

Laqueur, T. (1992). Making sex: Body and gender from the Greeks to Freud. Harvard University Press. 
Letsike, M. S. (2011). The "Steve" in me has a right. In A. Diesel (Ed.), Reclaiming the L-word: Sappho's daughters out in Africa (pp. 145-160). Modjaji. Lev, A. (2004). Transgender emergence. Haworth.

Lev, A. I. (2006). Disordering gender identity: Gender Identity Disorder in the DSM-IV-TR. Journal of Psychology and Human Sexuality, 17(3-4), 35-69.

Levine, L. (1994). Men in women's clothing: Anti-theatricality and effeminization 1579-1642. Cambridge University Press.

Levitt, H. M., \& Ippolito, H. R. (2014). Being transgender: The experience of transgender identity development. Journal of Homosexuality, 61, 1727-1758.

Levy, A. (2006). Female chauvinist pigs: Women and the rise of raunch culture. Free Press.

Lockman, D. (2019). All the rage: Mothers, fathers, and the myth of equal partnership. Harper.

MacKinnon, C. A. (1989). Toward a feminist theory of the state. Harvard University Press.

Markman, E. R. (2011). Gender Identity Disorder, the gender binary, and transgender oppression: Implications for ethical social work. Smith College Studies in Social Work, 81(4), 314-327.

Marotti, A. (1982). "Love is not love": Elizabethan sonnet sequences and the social order. ELH, 49, 396-428.

McClelland, S. (2010). Intimate justice: A critical analysis of sexual satisfaction. Social and Personality Psychology Compass, 4(9), 663-680.

McKenzie, S. (2010). Genders and sexualities in individuation: Theoretical and clinical explorations. Journal of Analytical Psychology, 55, 91-111.

Mendes, K., Ringrose, J., \& Keller, J. (2018). \#MeToo and the promise and pitfalls of challenging rape culture through digital feminist activism. European Journal of Women's Studies, 25(2), 236-246.

Mitchell, J. (1982). Introduction I. In J. Mitchell \& J. Rose (Eds.), Feminine Sexuality: Jacques Lacan and the école freudienne (pp. 1-26). Norton.

Morgan, R., \& Wieringa, S. (Eds.). (2005). Tommy boys, lesbian men and ancestral wives: Female same-sex practices in Africa. Jacana.

Muholi, Z. (2011). Thinking through lesbian rape. In A. Diesel (Ed.), Reclaiming the L-word: Sappho's daughters out in Africa (pp. 187-199). Modjaji.

Muholi, Z. (2018). Somnyama Ngomyama: Hail the dark lioness. Aperture.

Munro, B. M. (2012). South Africa and the dream of love to come: Queer sexuality and the struggle for freedom. University of Minnesota Press.

Namaste, V. K. (2000). Invisible lives: The erasure of transsexual and transgendered people. University of Chicago Press. 
Nkabinde, N. (2009). Black bull, ancestors and me: My life as a lesbian sangoma. Fanele.

O'Shea, S. C. (2020). 'I, Robot?' Or how transgender subjects are dehumanized. Culture and Organization, 1(26), 1-13.

Orgel, S. (1996). Impersonations: The performance of gender in Shakespeare's England. Cambridge University Press.

Peleg-Koriat, I., \& Klar-Chalamish, C. (2020). The \#MeToo movement and restorative justice: Exploring the views of the public. Contemporary Justice Review, 23(3), 239-260.

Perry, I. (2018). Vexy thing: On gender and liberation. Duke University Press.

Peterson, Z. D., \& Muehlenhard, C. L. (2007). Conceptualizing the "wantedness" of women's consensual and nonconsensual sexual experiences: Implications for how women label their experiences With rape. Journal of Sex Research, 44(1), 72-88.

Prosser, J. (1998). Second skins: The body narratives of transsexuality. Columbia University Press.

Pyne, J. (2014). Gender independent kids: A paradigm shift in approaches to gender non-conforming children. Canadian Journal of Human Sexuality, 23(1), 1-8.

Pyne, J. (2016). Queer and trans collisions in the classroom: A call to throw open theoretical doors in social work education. In S. Hillock \& N. J. Mule (Eds.), Queering social work education (pp. 54-72). University of Washington Press.

Raymond, J. (1979). The transsexual empire: The making of the she-male. Beacon. Reid, G. (2005). "A man is a man completely and a wife is a wife completely": Gender classification and performance amongst "ladies" and "gents" in Ermelo, Mpumalanga. In G. Reid \& L. Walker (Eds.), Men behaving differently: South African men since 1994 (pp. 205-227). Double Storey.

Reid, G. (2008). "This thing" and "that idea": Traditional responses to homosexuality and same-sex marriage. In M. Judge, A. Manion, \& S. de Waal (Eds.), To have \& to hold: The making of same-sex marriage in South Africa (pp. 73-86). Fanele.

Rich, A. (1980). Compulsory heterosexuality and the lesbian existence. Signs, 5(4), 631-660.

Rippon, G. (2019). The Gendered Brain: The new neuroscience that shatters the myth of the female brain. Penguin. 
Rodino-Colocino, M. (2018). Me too, \#MeToo: countering cruelty with empathy. Communication and Criticall Cultural Studies, 15(1), 96-100.

Rose, J. (1986). Sexuality in the field of vision. Verso.

Rose, N. (1998). Inventing our selves: Psychology, power, and personhood. Cambridge: Cambridge University Press.

Rutherford, A. (2018a). What the Origins of the "1 in 5" Statistic Teaches Us About Sexual Assault Policy. Behavioral Scientist, September 17. Retrieved April 27, 2021, from https://behavioralscientist.org/what-the-origins-ofthe-1-in-5-statistic-teaches-us-about-sexual-assault-policy/\#::text=Alexandra $\% 20$ Rutherford $\% 20 \mathrm{is} \% 20 \mathrm{a} \% 20$ professor,and $\% 20 \mathrm{its} \% 20$ impact\%20on\%20policy

Rutherford, A. (2018b). Feminism, psychology, and the gendering of neoliberal subjectivity: From critique to disruption. Theory \& Psychology, 28(5), 619-644.

Saini, A. (2017). Inferior: How science got women wrong - And the new research that's rewriting the story. Beacon.

Saketopoulou, A. (2014). Mourning the body as bedrock: Developmental considerations in treating transsexual patients analytically. Journal of the American Psychoanalytic Association, 62(5), 773-805.

Schiebinger, L. (1989). The mind has no sex? Women in the origins of modern science. Harvard University Press.

Schiebinger, L. (2004). Nature's body: Gender in the making of modern science. Rutgers University Press.

Serano, J. (2016). Whipping girl (2nd ed.). Seal Press.

Sideris, T. (2005). "You have to change and you don't know how!": Contesting what it means to be a man in a rural area of South Africa. In G. Reid \& L. Walker (Eds.), Men behaving differently: South African men since 1994 (pp. 111-138). Double Storey.

Solnit, R. (2014). Men explain things to me. Dispatch.

Solnit, R. (2018). Call them by their true names: American crises (and essays). Haymarket.

Spade, D. (2003). Resisting medicine, re/modeling gender. Berkeley Women's Law Journal, 18, 14-37.

Spurlin, W. (2010). Broadening postcolonial studies/decolonizing queer studies. In J. C. Hawley (Ed.), Post-colonial, queer: Theoretical intersections (pp. 185-205). SUNY Press.

Stryker, S. (2008). Transgender history. Seal.

Tatum, B. D. (1997). Why are all the black kids sitting together in the cafeteria? In And other conversations about race. Basic. 
Thomas, E. J., Stelzl, M., \& Lafrance, M. N. (2017). Faking to finish: Women's accounts of feigning sexual pleasure to end unwanted sex. Sexualities, 20(3), 281-301.

Tosh, J. (2016). Psychology and gender dysphoria: Feminist and transgender perspectives. Routledge.

Trengrove-Jones, T. (2008). Marriage and murder. In M. Judge, A. Manion, \& S. de Waal (Eds.), To have \& to hold: The making of same-sex marriage in South Africa (pp. 182-192). Fanele.

Trust Deficit. (2020). The Economist, December 19, pp. 72-74.

Valentine, D. (2007). Imagining Transgender: An ethnography of a category. Duke University Press.

Van Zyl, M. (2009). Beyond the Constitution: From sexual rights to belonging. In M. Steyn \& M. van Zyl (Eds.), The prize and the price: Shaping sexualities in South Africa (pp. 364-387). HSRC Press.

Vickers, N. (1981). Diana described: Scattered women and scattered rhyme. Critical Enquiry, 8(2), 265-278.

Wall, W. (1993). The imprint of gender: Authorship and publication in the English Renaissance. Cornell University Press.

Ward, J. (2020). The tragedy of heterosexuality. New York University Press.

Wieringa, S. (2005). Chapter nine. In R. Morgan \& S. Wieringa (Eds.), Tommy Boys, Lesbian Men and Ancestral Wives: Female same-sex practices in Africa (pp. 281-305). Jacana.

Wiggins, T. B. D. (2020). A perverse solution to misplaced distress: Trans subjects and clinical disavowal. Transgender Studies Quarterly, 7(1), 56-76.

Wilkinson, W. (2015). Born on the edge of race and gender: A voice for cultural competency. Hapa Papa.

Yeskel, F. (2015). Opening Pandora's box: Adding classism to the agenda. In S. M. Shaw \& J. Lee (Eds.), Women's voices feminist visions: Classic and contemporary readings (6th ed., pp. 95-100). McGraw-Hill.

Young, J. L., \& Hegarty, P. (2019). Reasonable men: Sexual harassment and norms of conduct in social psychology. Feminism \& Psychology, 29(4), 435-474. Zhou, J., Hofman, M. A., Gooren, L. J. G., \& Swaab, D. F. (2007). A sex difference in the human brain and its relation to transsexuality. In G. Einstein (Ed.), Sex and the brain (pp. 775-779). MIT Press. 
Open Access This chapter is licensed under the terms of the Creative Commons Attribution 4.0 International License (http://creativecommons.org/licenses/ by/4.0/), which permits use, sharing, adaptation, distribution and reproduction in any medium or format, as long as you give appropriate credit to the original author(s) and the source, provide a link to the Creative Commons licence and indicate if changes were made.

The images or other third party material in this chapter are included in the chapter's Creative Commons licence, unless indicated otherwise in a credit line to the material. If material is not included in the chapter's Creative Commons licence and your intended use is not permitted by statutory regulation or exceeds the permitted use, you will need to obtain permission directly from the copyright holder.

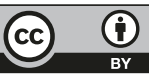

